\title{
EXCLUSIÓN, AUTONOMÍA E INTERVENCIÓN SOCIAL: REFLEXIONES A PARTIR DEL ANÁLISIS SOCIO-ANTROPOLÓGICO DE LA LEY DE RENTA MÍNIMA DE INSERCIÓN DE LA COMUNIDAD SOCIAL
}

\author{
Ariadna Ayala Rubio \\ Doctora en Antropología Social. Consejera pedagógica, \\ Cellule d'innovation pédagogique IDEA (Comue Université Paris-Est) \\ Investigadora asociada del laboratorio de Investigación \\ LIRTES (Université Paris-Est Créteil) \\ ariadna.ayalarubio@univ-paris-est.fr \\ Débora Ávila Cantos \\ Doctora en Antropología Social. Profesora Titular Interina \\ Departamento de Antropología Social y Psicología Social \\ Facultad de Ciencias Políticas y Sociología \\ Universidad Complutense de Madrid \\ deboraav@ucm.es
}

\section{LA RMI EN LA COMUNIDAD DE MADRID}

La Ley de Renta Mínima de Inserción de la Comunidad de Madrid, promulgada a finales del año 2001, reconoce y garantiza a los ciudadanos madrileños dos derechos sociales: por un lado, la asignación de una prestación económica a las personas que cumplan determinados requisitos y, por otro, el derecho a la inserción social, el cual se hace efectivo mediante apoyos personalizados para la misma (Ley 15/2001: 1). Esta prestación sustituye y amplía la anterior, el Ingreso Madrileño de Integración, que se encontraba únicamente regulado a nivel de decretos ${ }^{1}$, dotando a

\footnotetext{
${ }^{1}$ Decreto 73/1990, de 19 de julio, que regula el Ingreso Madrileño de Integración (BOCM de 28 de septiembre de 1990); Decreto 80/1990, de 20 de septiembre, del Consejo de Gobierno, por el que se modifica el Decreto 73/1990, de 19 de julio, que regula el Ingreso Madrileño de Integración (BOCM de 28 de septiembre de 1990); Orden 178/1991, de 22 de marzo, de la Consejería de Integración Social, que desarrolla los Decretos 73/1990, de 19 de julio, y 80/1990, de 20 de septiembre, reguladores del Ingreso Madrileño de Inte-
} 
la Renta Mínima de Inserción (en adelante, RMI) de un mayor rango jurídico y situándola «en el contexto más amplio de los sistemas públicos de protección estatales, en cuanto que viene a proteger situaciones de desvalimiento o especial vulnerabilidad no previstas en aquellos» (Decreto $147 / 2002$ : 4).

Así, mediante el reconocimiento de los dos derechos mencionados (prestación económica y apoyos sociales para la inserción social) se establecen criterios para la concesión de la prestación y nuevos mecanismos de gestión de la misma, suponiendo a nivel formal una garantía para los ciudadanos, dado que al ser una prestación garantizada por derecho puede ser reclamada y exigida por cualquier persona que cumpla los requisitos ${ }^{2}$. De esta manera, la RMI ha convertido los apoyos a la inserción ${ }^{3}$ en derecho de protección social.

Lo esencial de la Ley RMI se refiere al reconocimiento y desvinculación, a nivel formal, de los dos derechos, estableciendo una nueva relación entre dos lógicas, la de la prestación económica y la de las actividades de inserción o apoyos sociales ${ }^{4}$.

Esta separación entre las dos lógicas (figura 1) aparece mencionada, sin embargo, únicamente en la exposición de motivos de la ley (Ley 15/2001: 10), no quedando en este texto especificada herramienta alguna que materialice protocolos o actuaciones concretas para su puesta en práctica. En la práctica, son los trabajadores de servicios sociales los que realizan esta labor, por lo que la separación entre las dos lógicas que se

gración (BOCM de 11 de abril de 1991; corrección de errores en BOCM de 22 de abril de 1991), y Orden 234/1992, de 4 de mayo, de la Consejería de Integración Social, por la que se desarrolla el Decreto 21/1992, de 24 de abril, relativo al Ingreso Madrileño de Integración (BOCM de 4 de mayo de 1992).

2 J. M. Alonso, «Nuevos derechos en la Comunidad de Madrid para las personas socialmente excluidas. Breve apunte sobre la Ley de Renta Mínima de la Comunidad de Madrid», Revista del Ministerio de Trabajo y Asuntos Sociales, núm. 35 (2002), pp. 185-198.

${ }^{3}$ En los tiempos de la RMI, a diferencia de la época de implementación del IMI, hay una preferencia por el término «inserción» y un rechazo del término «integración», adjudicándosele a este connotaciones negativas relacionadas — como se ha apuntado más atrás—con tentativas de asimilación y homogeneización de las personas con dificultades a partir del uso de un modelo implícito basado en la población considerada «normal». Vid. M. A. MarTínez ROMÁN, «Género, pobreza y exclusión: diferentes conceptualizaciones y políticas públicas», en J. M. TorTosa (coord.), Pobreza y perspectiva de género, Barcelona, Icaria, 2001, p. 76.

${ }^{4}$ La compleja naturaleza del vínculo entre renta mínima e inserción se aborda desde las concepciones más abiertas, como la del «doble derecho» (derecho a la renta mínima y derecho a la inserción social), hasta las más autoritarias, como la de la inserción como «contrapartida o condición» para acceder a la renta mínima. Vid. M. AgUILAR, M. GAVIRIA y M. LAPARRA, La caña y el pez. Estudio sobre los salarios sociales en las Comunidades Autónomas, 19891994, Madrid, Fundación FOESSAM, 1995, p. 36. 
FigURA 1

Las diferentes lógicas a las que responden los dos derechos reconocidos por la $R M I$

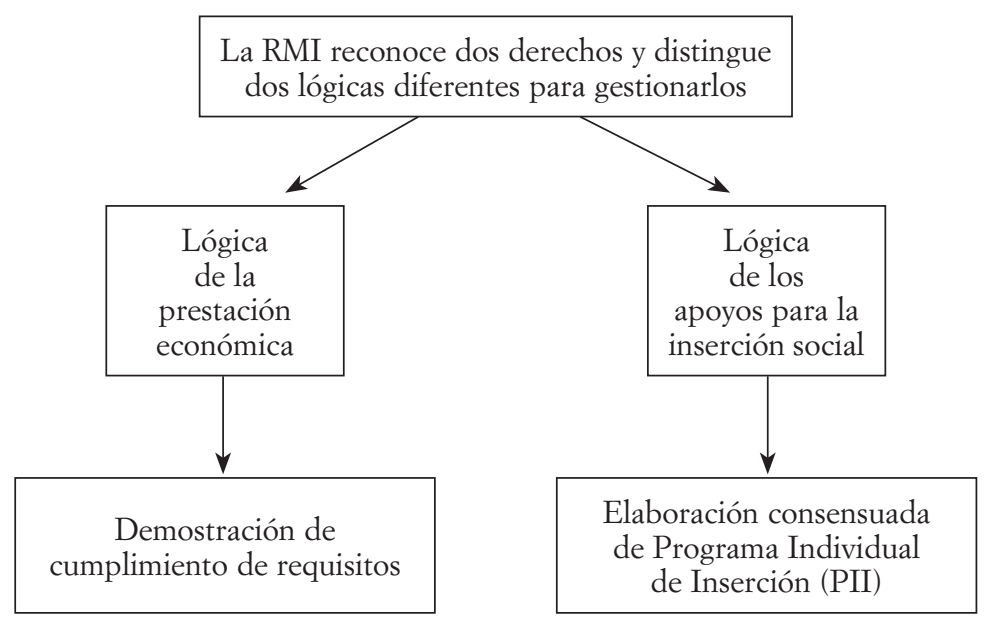

Fuente: Elaboración propia.

afirma en la ley se dificulta debido a la coincidencia de funciones referidas a ambas en la figura del trabajador social. Este, en cierto sentido, sigue desarrollando quehaceres relativos al control de los requisitos para acceder a la RMI, por lo que los solicitantes pueden fácilmente percibirle como alguien con autoridad para influir en la concesión o suspensión de la prestación económica. En todo caso, un aspecto verdaderamente novedoso de la gestión de la renta mínima en la Comunidad de Madrid es que, a diferencia de lo que sucedía con la política anterior, los trabajadores de servicios sociales no tienen poder decisional para retirar o suspender la prestación económica 5 .

Otro aspecto innovador de la ley que rige la RMI es el establecimiento de un procedimiento sancionador. Se trata de un sistema administrativo que regula las suspensiones y extinciones de la prestación y establece una jerarquía de obligaciones y sanciones para aquellos que incumplan

5 Es la Consejería competente de la Comunidad de Madrid la encargada, por un lado, de valorar la concesión o denegación de la prestación y, por otro, de iniciar los trámites relativos a la suspensión y extinción de la misma (Ley 15/2001: 24-27, y Decreto 147/2002: 36-44). 
sus compromisos. El incumplimiento de alguna de las medidas que se consignan en ellos es una de las causas recogidas en el procedimiento sancionador que generan una amonestación por infracción leve (y la acumulación de varias de ellas puede conllevar la extinción de la RMI) (Decreto 147/2002: 49). De este modo, el rol del trabajador social aparece vinculado —en cuanto «informante» o transmisor de datos sobre los usuarios a la Comunidad de Madrid (en adelante, CM) — a las posibles sanciones o amonestaciones que reciban los perceptores de la prestación económica. Así, estos profesionales siguen cumpliendo una función que fácilmente se asocia — como expresan la mayoría de los beneficiarios de la RMI entrevistados $-{ }^{6}$ con el peligro de perderla. En estas circunstancias es difícil que estos no perciban con cierta desconfianza el rol del trabajador social. Así, podemos sostener que la vinculación de su labor con la posibilidad de iniciar un procedimiento sancionador se convierte en un poderoso disuasivo que imposibilita el cumplimiento de algunos de sus principales objetivos; entre ellos, el de lograr establecer una relación cercana con los usuarios de la RMI que permita la elaboración (negociada y consensuada) del Programa Individual de Inserción (en adelante, PII) o antiguo Contrato de Integración.

Así, se establece un proceso o itinerario individualizado que deberá «contar con la participación y consentimiento de las personas a quienes se dirige» (Decreto 147/2002: 56-60). Esta idea de elaboración conjunta y negociada del PII supone una ruptura con la concepción más asimétrica de la relación trabajador social-usuario que regía la aplicación de la política social precedente, el Ingreso Madrileño de Integración (en adelante, IMI):

«A fin de favorecer su eficacia, deberá contarse con la participación y consentimiento de los usuarios [...] Cada programa individual de inserción deberá ajustarse a las circunstancias, capacidades y preferencias de las personas a quien se dirige» (Ley 15/2001: 36-37).

Para terminar este apartado quisiéramos mencionar rápidamente el aspecto relativo a la difícil gestión de la RMI. La complejidad de los trá-

${ }^{6}$ Gracias a una beca del Programa de Formación del Profesorado Universitario (FPU), la autora pudo realizar, entre mayo de 2006 y agosto de 2008, trabajo de campo etnográfico en varios asentamientos chabolistas de la Comunidad de Madrid (Santa Catalina, El Cañaveral y dos zonas de la Cañada Real Galiana), así como entrevistas en profundidad a treinta y nueve personas de etnia gitana beneficiarias de la RMI y a treinta y dos profesionales del ámbito de la intervención sociosanitaria de la Comunidad de Madrid. 
mites administrativos conducentes a su concesión y el hecho de que son diferentes instituciones (Ayuntamiento y Comunidad de Madrid) las que los realizan añade un elemento de dificultad extra que marca los discursos de los entrevistados. En esta misma línea, el establecimiento de requisitos de concesión y de un trámite anual de revisión de los mismos exige que se pida frecuentemente la entrega de documentación, además de informes de los profesionales sobre el cumplimiento, por parte de los usuarios, de las medidas que aparecen en los PII. Dicha complejidad administrativa que rodea cotidianamente a los trámites de la RMI ha sido señalada como uno de los principales obstáculos a la efectiva implementación de este tipo de políticas sociales. Complejidad que se ha incrementado, de modo paradójico, con la descentralización o el intento de acercar hasta los usuarios, a nivel de las Comunidades Autónomas y/o de los ayuntamientos, procesos cuya gestión se quiso facilitar con ello ${ }^{7}$.

\section{ALGUNOS FACTORES CONCERNIENTES A LA AMBIGÜEDAD DE LA LEY}

El estudio de la Ley RMI y del real decreto que la regula nos ha llevado a detectar diversos aspectos que dificultan una aplicación coherente de la RMI, como son la no separación, en la práctica, de los dos derechos que la ley reconoce, la ambigüedad de la función que se les atribuye a los trabajadores sociales (relativa a posesión o no de autoridad para «controlar» la prestación económica), la falta de regulación de mecanismos de control que garanticen que el diseño de la intervención social sea efectivamente consensuado y la vaguedad que afecta, asimismo, a las sanciones que se pueden imponer por la falta de cumplimiento por parte de los usuarios de las actividades que aparecen en el PII. En este apartado trataremos de explicitar algunas de estas contradicciones, para así tratar de identificar los aspectos formales y estructurales que están posibilitando interpretaciones y aplicaciones dispares de la ley.

7 S. Ramírez Hita, Gitanos y salud. Articulación de prácticas y saberes médicos entre los gitanos de Perpignan, tesis de doctorado, Universidad Rovira i Virgili de Tarragona, 2003, pp. 86 y 92.

Esa descentralización, sin embargo, se ha acompañado del establecimiento de jerarquías y fragmentaciones entre los distintos organismos de gestión, así como de la subcontratación de empresas y ONGs para la realización del trabajo de intervención más continuado, lo que introduce nuevos elementos de decomplejización en la cadena de intervención social. 


\section{Dos lógicas de acción separadas, pero no realmente...}

La ley cuenta — como se ha adelantado en el apartado anterior- con contradicciones internas referentes a la separación promulgada de los dos derechos que regula: derecho a una prestación económica y derecho a apoyos sociales para la inserción. Mientras que en la presentación de la misma se define la RMI como derecho subjetivo y se distinguen los dos mencionados, la ley se vuelve contradictoria al establecer, en el resto de su articulado, la obligatoriedad de la participación en actividades de inserción (Ley 15/2001: 23). Por tanto, podríamos decir que, a efectos reales, no separa los dos derechos de los que habla, sino que los une al establecer que la persona que cobre la RMI ha de firmar obligatoriamente un PII y cumplir las actividades en él descritas: «Participar activamente en la ejecución de las medidas contenidas en el PII elaborado por el centro de servicios sociales correspondiente» (Decreto 147/2002: 33). De este modo, después de que el profesional de servicios sociales realiza el diagnóstico social de la persona beneficiaria de la RMI, se pasa a desarrollar el PII y, una vez que lo firma, los compromisos que en él se establecen pasan a formar parte de sus obligaciones.

Esta contradicción (que tiene como efecto el que no sea «real» la distinción de los dos derechos) aparece expresada de manera resumida en el siguiente cuadro (figura 2), donde podemos ver que la obligatoriedad de la suscripción del PII por parte del perceptor de la RMI vincula las dos lógicas que la ley aparentemente pretende disociar.

También se puede apreciar que la ley no separa realmente los dos derechos en el hecho de que el incumplimiento por parte de los usuarios de las actividades establecidas en el PII tiene consecuencias sobre la continuidad del cobro de la prestación ${ }^{8}$.

Martín Giner' ha señalado que esta ambigüedad de la ley facilita la conceptualización de la RMI como una prestación condicionada, que obliga a que los beneficiarios de la misma estén vinculados a un profesional de servicios sociales:

\footnotetext{
8 Así, según los datos del Balance de gestión de la RMI 2010, de los procedimientos sancionadores emprendidos ese año que acabaron en extinciones de la misma, veintiuno de ellos se iniciaron debido al incumplimiento de los compromisos suscritos en los PII, y del total de los abiertos por cualquier causa (79), el 50 por 100 se resolvió con la retirada de la prestación de la RMI como sanción.

9 A. Martín Giner, «La Renta Mínima de Inserción: contradicciones e incertidumbres», Cuadernos de Trabajo Social, vol. 20 (2007), pp. 297-307.
} 
FIGURA 2

La interrelación entre los dos derechos que la ley pretende separar

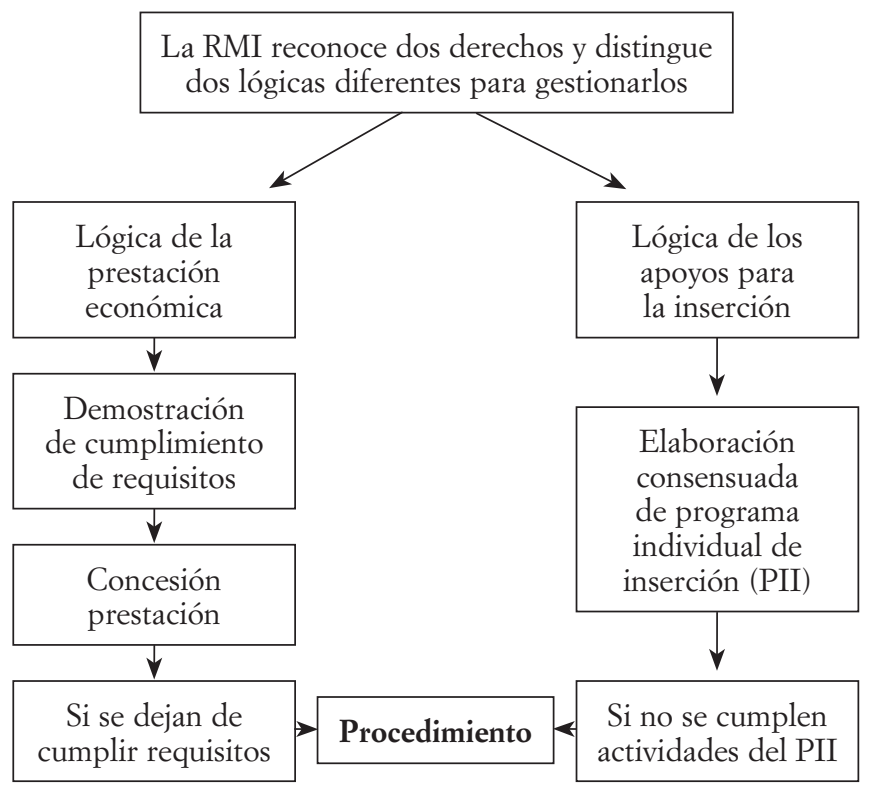

Fuente: Elaboración propia.

«De un lado, se dice que es una prestación de derecho: "derecho subjetivo" (el derecho que tiene cualquier ciudadano de reclamar para sí la aplicación de una norma, esto es, la aplicación de la Ley RMI), por lo que se elimina el concepto de "prestación graciable". Sin embargo, se sigue hablando de una renta de inserción condicionada, ya que se concede en determinadas condiciones de rentas y obligaciones, vinculándola a la intervención de un profesional» ${ }^{10}$.

Dicha ambigüedad genera controversia en torno a esta cuestión entre los profesionales de servicios sociales y los expertos entrevistados, lo que indica que existen formas diferenciales y contradictorias de interpretarla. Así, algunos conciben la RMI como un derecho condicionado al cum-

\section{${ }_{10}$ Ibid.}


plimiento de las actividades de inserción, siendo estas entendidas como la contraprestación que, mediante un acto de reciprocidad, hacen los beneficiarios por el dinero otorgado por el Estado:

«En cualquier caso, eres un profesional de los servicios sociales y ellos están vinculados a servicios sociales porque tienen una prestación y, entonces, tiene que haber un trabajo. No es un derecho subjetivo, o sea, que aunque ahora como renta mínima se diga que es una prestación por derecho, no es como tal, porque está condicionada y vinculada a un proyecto de integración» (entrevista a extrabajadora de servicios sociales en mancomunidad madrileña, treinta y siete años).

En cambio, otros consideran que la RMI debería ser un derecho social no condicionado, por lo que se tendría que imposibilitar su uso como herramienta para forzar la participación en procesos de inserción. Así, desde el primer tipo de posicionamiento (no así desde este segundo, por otro lado minoritario entre los profesionales) se construye la idea de la contraprestación obligatoria, naturalizándose y divulgándose en diversos foros profesionales, es decir, tratándose como si «viniera de por sí»». Un ejemplo de ello lo encontramos en la afirmación de Molleda, directora de un Centro de Servicios Sociales, quien sostiene lo siguiente a este respecto:

«Un ejemplo: enviamos a una persona perceptora de una renta mínima a un proyecto de búsqueda de empleo porque el cobro de la renta mínima exige una contrapartida, porque obtener un empleo es una buena forma de prescindir de la renta mínima, porque su programa individual de inserción así lo exige» ${ }^{11}$ (cursivas nuestra).

Las palabras que se utilizan en este y en otros discursos correspondientes a profesionales que intervienen en este ámbito (como, por ejemplo, «se exige») afirman la obligatoriedad de la participación y enfocan los instrumentos técnicos vinculados a la RMI como impersonalizados, sobre los que los profesionales no tuvieran control alguno, obviando especificar que el PII, por ley, debe ser consensuado con la persona que lo va a llevar a cabo y que no propiciar ese consenso o no informar a los beneficiarios de los nuevos derechos que les amparan es una decisión personal del profesional. Por

11 E. Molleda, «¿Por qué decimos que "no podemos hacer intervención social”?», Cuadernos de Trabajo Social, núm. 20 (2007), p. 142. 
tanto, el PII, en sí mismo, no es una figura que obligue a nada, sino que es una herramienta para concretar aquello a lo que el usuario está dispuesto a comprometerse de cara a mejorar su situación actual. En todo caso, autores como Duvoux ${ }^{12}$ hacen referencia a que el propio hecho de que adopte la forma de un contrato lleva consigo, a nivel simbólico, una serie de implícitos sociales; entre ellos, la idea de que firmarlo implica obligatoriedad por ambas partes:

«Los proyectos de integración, claro, son una herramienta dentro del segundo derecho, el derecho a apoyos personalizados para la incorporación social y laboral. La garantía de ingresos y el derecho a los apoyos teóricamente son derechos independientes, aunque en el caso del perceptor sí que está obligado a un proceso, consensuado en teoría, pero (está obligado) a hacer algo» (entrevista a técnica de la CM, cincuenta años).

De este modo, la ambigüedad de la ley y la resignificación que de esta realizan los profesionales, tendentes a asemejarla a la prestación predecesora (el IMI), hacen plausibles interpretaciones divergentes que están afectando a su aplicación.

\section{Una misma categoría profesional, dos funciones contradictorias: entre el control, la gestión y el ideal de acompañamiento social}

Otro aspecto que no queda definido sin vaguedades en los documentos que regulan la RMI es el contenido concreto de las funciones de los trabajadores de servicios sociales, quienes tienen que asumir tareas concernientes a la gestión de las dos lógicas que establece la ley (vid. figura 3).

Estos profesionales están autorizados para supervisar e informar a la Consejería de los requisitos de acceso a la prestación económica y de los compromisos adquiridos por parte de los usuarios que no se cumplen. La coincidencia en el mismo profesional de funciones ${ }^{13}$, por una parte, de control y/o vigilancia del cumplimiento de requisitos para recibir/mantener la RMI y, por otra, relacionadas con el diseño de la intervención social para dar los apoyos sociales correspondientes entraña una de las principales

${ }^{12}$ N. Duvoux, L'autonomie des assistés. Sociologie des politiques d'insertion, Paris, Presses Universitaires de France, 2009.

13 D. Ávila y M. Malo, «Manos invisibles. De la lógica neoliberal en lo social», Trabajo Social Hoy, núm. 39 (2010), pp. 137-171. 
FIGURA 3

Funciones de los trabajadores de servicios sociales

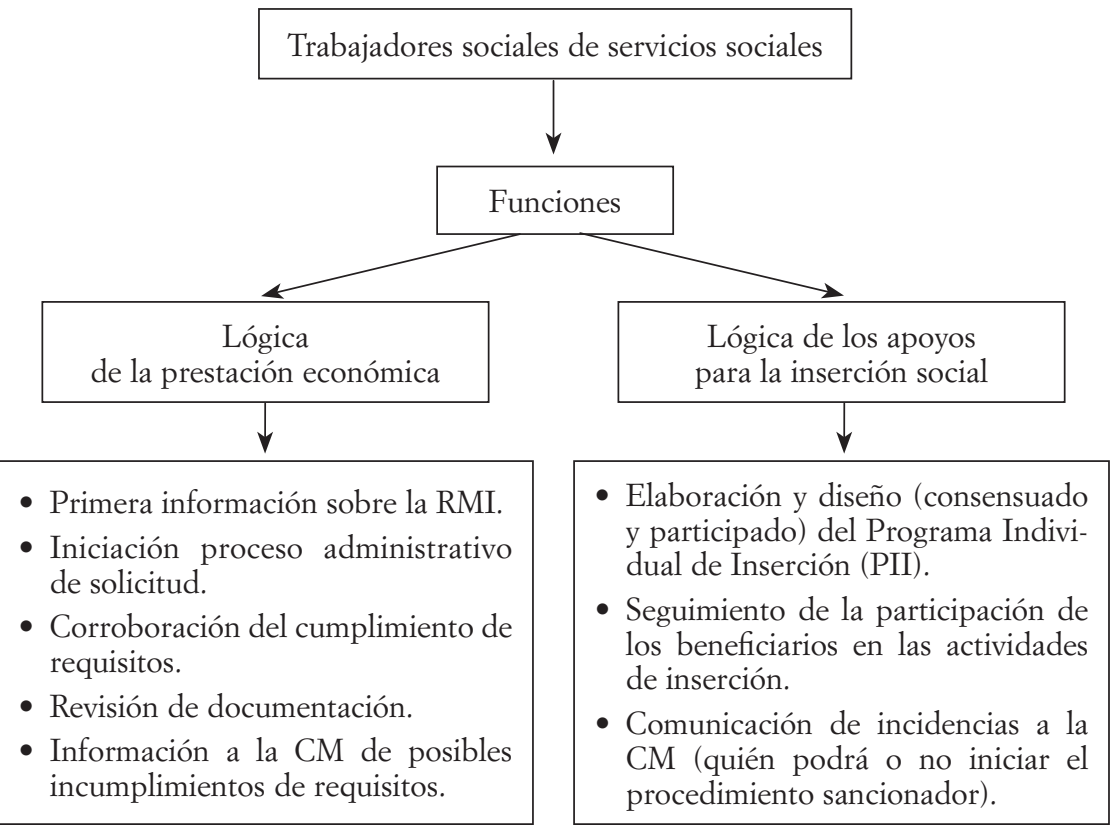

Fuente: Elaboración propia.

dificultades de la aplicación de la ley. Entre otros motivos, porque esos usuarios, debido a ello, no se fían de los trabajadores de servicios sociales ${ }^{14}$. Ello entorpece que la elaboración de la intervención social responda a los intereses, demandas y circunstancias de los usuarios, puesto que estos no pueden arriesgarse a tener conflictos con quienes disponen de influencia sobre la continuidad del cobro de la prestación económica. Por tanto, aceptan suscribir el PII estipulado por estos profesionales con tal de no tener problemas, en detrimento de la coparticipación en la preparación de una intervención social adaptada ${ }^{15}$. Es más, se puede aventurar que el

${ }^{14}$ S. García García, «Hermenéutica de la queja (o análisis del micropoder en los servicios sociales)», Trabajo Social Hoy, núm. 44 (2005), p. 11.

15 Otro factor que afecta a que la elaboración del PII no sea verdaderamente consensuada es el corto periodo de tiempo que establece la Ley RMI para su firma, siendo de un mes desde que se concede la prestación, aunque actualmente la Consejería está ampliando el plazo a seis meses. 
hecho de que la participación se conciba como obligatoria por profesionales y solicitantes/beneficiarios, como una contraprestación, influye en que estos últimos no se interesen realmente por las propias actividades previstas para su proceso de inserción social.

\section{3. ¿Obligatoriedad o no obligatoriedad? El caso de Alma}

Un ejemplo de confusión en lo que se refiere a la obligatoriedad de suscribir un PII es el caso de Alma ${ }^{16}$, una mujer gitana de veintiún años de origen extremeño que reside en una vivienda ocupada en el barrio madrileño de Colonia Jardín. En el momento de solicitar la RMI le dijo a su trabajador social de zona que estaba, a efectos prácticos, separada. En ese momento tenía un hijo de un año. Su trabajador social, que entendía que no era su papel presionar en exceso para que Alma participara en actividades de inserción, le hizo firmar un PII donde básicamente solo se enumeraba que iba a comenzar alguna actividad de búsqueda de empleo, además de las visitas periódicas a servicios sociales para la renovación del PII. En la entrevista que, en el marco de este estudio, le realizamos a una beneficiaria gitana llamada Alma, cuando le preguntamos si sabía que podía tener voz acerca de qué incluir en su PII y le informamos de que una vez que se firma ese documento sí que adquiere un carácter obligatorio, comentó: «Ya sabía yo que me estaban engañando» ${ }^{17}$. Y si bien es cierto que su trabajador social, por concebir la RMI como un derecho de protección social, no trató de convencerla para que participara en proyectos de integración (incluso ha faltado a varias reuniones con él y no ha informado a la CM), el hecho de que Alma sienta que ha sido engañada da cuenta de dos fenómenos: por un lado, que concibe la prestación desde la desconfianza, elemento omnipresente en la relación entre usuarios y trabajadores sociales en el periodo IMI, y, por otro, que no ha contado con suficiente información de cómo funciona la RMI y qué elementos de esta puede utilizar para tomar parte efectivamente (con conciencia y conocimiento) en la elaboración de su itinerario de inserción y en la firma de los distintos documentos de demanda y renovación de la RMI. Alma siente que ir a servicios sociales no conlleva que se le ayude en nada de lo que necesita. Aun así, y por la

\footnotetext{
16 Nombre ficticio.

17 Fue esta una de las pocas veces que preguntamos directamente, durante la realización de las entrevistas, si sabía que no se le podía obligar a firmar el PII.
} 
«buena relación» con su trabajador social, suele aparecer periódicamente por el centro donde este trabaja para charlar con él, pero sobre todo para insistir en la demanda de alguna «ayuda de emergencia» cuya existencia ha conocido por medio de algún familiar. Se podría sostener que ir de vez en cuando a reunirse con los trabajadores sociales se vivencia como una estrategia «preventiva» de cara a no poner en riesgo el cobro de la prestación económica de la RMI ${ }^{18}$.

\section{Trabajo social y acompañamiento social: una misión imposible en el marco actual de la RMI}

La confusión, además de originarse en la mezcolanza de funciones que han de cumplir los profesionales de servicios sociales, se acrecienta como consecuencia de lo que establecen ciertos documentos oficiales de la CM, que divulgan mensajes divergentes y, a veces, contradictorios con lo expresado por la legislación de la RMI al dejar un amplio abanico de posibilidades para que los propios profesionales elijan aquellas funciones con las que más cómodos se encuentren. Así, mientras que la función del trabajador social definida en la legislación da pie a una intervención con cierto aspecto fiscalizador, en otros documentos oficiales, como el Plan contra la Exclusión Social 2002-2006, se obvia el aspecto del control y se define al trabajador social como aquel que acompaña, comprende y apoya a las personas en situación de exclusión. Se introduce así la noción de «acompañamiento social» como tarea estelar del profesional de servicios sociales, definiéndose como la relación personal continuada y relativamente duradera que trata de comprender y apoyar a las personas para contribuir a que ellas mismas empiecen a dominar su situación y las claves de sus dificultades. Se trata, por tanto, de contribuir a que las personas activen y movilicen recursos, capacidades y potencialidades tanto suyas como de su entorno.

Sin embargo, según varios trabajadores sociales entrevistados, esta función de «acompañamiento social» no se está llevando a cabo debido a la saturación de las agendas de estos profesionales y a la negativa de muchos de ellos a desarrollar trabajo de calle en un marco de trabajo social comu-

${ }^{18}$ En todo caso, las prenociones que los gitanos manejan sobre la RMI, así como la falta de formación escolar y de habilidades para la comprensión de los procedimientos oficiales, dificultarían probablemente, en el supuesto de ser informados, la comprensión de los aspectos más novedosos relativos a esta política social. 
nitario ${ }^{19}$. Además, la «fragmentación del espacio social de la intervención social ${ }^{20}$ ha supuesto la burocratización de la renta mínima, con una división de tareas entre el personal con mayor estabilidad laboral (de servicios sociales), que realiza las funciones más relacionadas con la gestión, el control y la documentación, y el más inestable (educadores sociales, psicólogos, pedagogos y demás profesionales de ONGs contratados con financiación a cargo de los proyectos de integración), que desempeñan las funciones educativas y de «acompañamiento social».

Es preciso señalar que el concepto de «acompañamiento social» no aparece ni en la Ley RMI ni en el decreto que la regula referido a la función de los trabajadores de servicios sociales, sino que se menciona exclusivamente en el apartado que alude a los proyectos de integración desarrollados por las entidades de iniciativa social (Ley 15/2001: 40; Decreto 147/2002: 68) o en los textos clásicos que evalúan los programas de rentas mínimas a nivel nacional ${ }^{21}$. Igualmente, solo dos de los trabajadores sociales entrevistados mencionan ese término, coincidiendo que ambos son personas que dan cursos de formación y tienen contacto con los documentos oficiales. El «acompañamiento social» es, por tanto, una categoría legitimada en el contexto de cursos formativos a profesionales de la intervención social y en los discursos de quienes, trabajando en condiciones precarias, quieren dotar de valor a su labor profesional. En general, los trabajadores de servicios sociales desconocen lo que dicho término implica y, cuando lo conocen, sostienen no poder realizar la función que supone por la cantidad de personas a las que tienen que atender, lo que les genera cierto desasosiego y frustración.

\section{Sobre la indeterminación de la «negociación» que describe la ley}

Por otro lado, lo que atañe a la negociación consensuada del proceso de inserción social de los usuarios de la RMI no queda regulado ni en la ley ni en el decreto, en donde no aparecen mecanismos ni herramientas destinadas a garantizar que el diseño de esa inserción sea realmente negociado y participado, como podría ser mediante la firma de un consentimiento informado que ratificara que se ha recibido información completa sobre los distintos elementos de la renta mínima antes de rubricar ninguna documenta-

19 A. Serrano y A. Arriba, ¿Pobres o excluidos? El Ingreso Madrileño en perspectiva comparada, Madrid, Fundación Argentaria, 1998, p. 187.

20 M. Aguilar, M. Gaviria y M. Laparra, La caña y el pez..., op. cit., p. 37.

${ }^{21}$ Ibid. 
ción vinculante. Se deja que cada trabajador de servicios sociales resuelva este tema a su modo, revelándose un vacío de contenidos en uno de los aspectos más novedosos de la actual ley ${ }^{22}$. Tampoco se hace referencia a qué mínimos han de aparecer en el PII, pudiendo establecerse cualquier actividad acorde con el diagnóstico social que realice el trabajador de servicios sociales. Por tanto, los profesionales pueden incluir en el PII unos mínimos «muy mínimos», como escolarizar a los hijos y acudir a controles pediátricos, o elaborar programas individuales de inserción que impliquen que los perceptores de la RMI tengan que asistir a talleres periódicos o a cursos de formación, pues la legislación no establece qué participación se les puede pedir; algo que ha sido destacado por autores como Olmeda ${ }^{23}$.

Podemos decir, a modo de resumen, que la legislación relativa a la RMI no logra separar los dos derechos que establece, produciéndose una serie de zonas grises, de vacíos o de dudas razonables que dan cabida a que cada profesional interprete y aplique la RMI de la forma que considere oportuna. Además, como se ha señalado, los elementos más novedosos de la Ley RMI, aquellos que podrían dotar de más poder y autonomía a los beneficiarios para iniciar procesos de toma de decisiones informadas y responsables sobre las actividades a las que están dispuestos a comprometerse, no aparecen regulados. En contraste con lo anterior, la forma en la que el procedimiento sancionador está redactado (incluyendo el riesgo de que la acumulación de sanciones leves legitime la retirada o la suspensión de la prestación económica) da pie a interpretaciones de la ley que abren la posibilidad de utilizar la existencia de dicho procedimiento sancionador como medio para presionar a los beneficiarios de la RMI a que participen en distintas actividades de inserción.

\section{EXCLUSIÓN, INTEGRACIÓN Y SUJETO LEGÍTIMO DE LA INTERVENCIÓN SOCIAL}

En los anteriores apartados se ha dado cuenta de la forma de funcionamiento de la RMI, de la complejidad de los procedimientos que entra-

${ }^{22}$ M. Aguilar, M. Gaviria y M. Laparra, El Programa Ingreso Madrileño de Integración (IMI). Primera evaluación, Madrid, Consejería de Integración Social, 1993, p. 137, apuntan, después de evaluar la implantación del IMI, el déficit de información con que cuentan los perceptores sobre cómo funciona el programa y la dificultad de los trabajadores sociales para establecer procesos de negociación con ellos.

${ }_{23}$ G. OLMEDA, «La renta mínima garantizada. A caballo de la asistencia, la seguridad social y la política de empleo», Revista de Treball, Economia i Societat, núm. 7 (1997), pp. 33-56. 
ña y de algunos de los factores que están dificultando su implementación En esta sección se analizan las concepciones de los profesionales que hacen referencia a la exclusión e integración social y a las características que se asocian al colectivo gitano. Estas concepciones guardan una estrecha relación con las estrategias concretas que estos profesionales despliegan en la aplicación de la RMI con los perceptores de la misma y, en especial, con los de etnia gitana, puesto que estos son los que, según expresan los entrevistados, les ocasionan más dilemas en la intervención social ${ }^{24}$.

A continuación analizaremos, en primer lugar, la visión de la exclusión y de la integración social que se desprende tanto de la Ley RMI como de algunos artículos escritos por trabajadores sociales, y defenderemos que la idea de sujeto excluido que estos textos amparan se configura a partir de ciertos valores inherentes a la clase media, en la que podemos situar a los profesionales que trabajan en el ámbito de la intervención social.

\section{Concepciones de la exclusión social en los textos reguladores de la RMI: ¿¿de quién se habla cuando la ley aborda la exclusión?}

Las concepciones de la exclusión social y de la integración que se manejan en la Ley 15/2001 y en el Decreto 147/2002 van configurando una imagen del sujeto que legítimamente puede demandar la prestación. Esta imagen de lo que es estar socialmente excluido no solo implica demostrar una necesidad económica o social, sino que naturaliza algunos valores morales que exaltan determinadas actitudes de los sujetos, como, por ejemplo, la buena predisposición para participar en actividades de inserción, el deseo de cambiar la propia vida y de ascender socialmente a través de la incorporación al mercado laboral formal ${ }^{25}$. De este modo, los sujetos que no cumplen lo que se espera de ellos (adhesión a dichos valores y/o demostración de las mencionadas actitudes) encuentran menor reco-

${ }^{24}$ Algunos de los principales dilemas de la intervención social con el colectivo gitano han sido presentados en A. Ayala Rubio, «Secretos a voces: exclusión social y estrategias profesionales de construcción de la obligatoriedad en la intervención social vinculada a la Renta Mínima de Inserción (RMI) con el colectivo de etnia gitana», Cuadernos de Trabajo Social, núm. 22 (2009), e íD., Las políticas sociales en perspectiva socioantropológica: estudio de la gestión y aplicación de la Renta Mínima de Inserción de la Comunidad de Madrid con el colectivo gitano, tesis doctoral, Universidad Complutense de Madrid, 2012.

${ }_{25}$ D. Ávila y M. Malo, «Manos invisibles...», op. cit. 
nocimiento por parte de los profesionales y son objeto de una intervención profesional más severa.

Mientras que en la exposición de motivos de la ley se mencionan las causas macroestructurales que producen condiciones de vulnerabilidad social y se hace referencia a cómo «las nuevas formas de desarrollo» generan problemas de exclusión social y propician que «algunos sectores de la población se vean gravemente obstaculizados para incorporarse plenamente al desarrollo social a causa de problemas diversos», en el resto del documento es destacable la tendencia a individualizar las causas de la exclusión social y a situar su origen en características personales de quienes están «en situación de exclusión social». Así, cuando se mencionan los problemas que impiden la incorporación de estas personas al «desarrollo social», cuatro de los cinco problemas enumerados son de índole individual: falta de adaptación a las nuevas exigencias del mercado de trabajo, problemas familiares y personales de diverso tipo, problemas de salud (y, en especial, de salud mental) y como quinto problema se hace referencia al único que, como se ha dicho, es de índole social: la «persistencia de prejuicios y discriminación de ciertos grupos sociales»:

«En la Comunidad de Madrid existen grupos de personas que tienen una acumulación de barreras y límites que les dificulta y, en ocasiones, les deja fuera de la participación en la vida social mayoritaria. Estas barreras vienen propiciadas por fuertes dificultades en el mundo de las relaciones familiares y sociales, bajos niveles culturales, dificultad para hacer efectivo el acceso a la salud, carencias laborales, dificultades para conseguir empleo y falta de acceso a una vivienda digna. Todos estos factores constituyen un evidente riesgo de marginación y exclusión social. Además, los cambios sociales, económicos y culturales acaecidos en los últimos años en nuestra región han hecho aflorar una gran diversidad de aspectos carenciales en personas, familias y grupos de población de la sociedad madrileña» (Orden 2675/2007, de 31 de diciembre, de la Consejería de Familia y Asuntos Sociales) ${ }^{26}$.

Esta tendencia a situar en el individuo las causas de la exclusión social coincide con una visión carencial y multiproblemática de los sujetos excluidos. Se habla de ellos como personas con múltiples carencias, barre-

${ }^{26}$ Por la que se aprueban las bases reguladoras para la concesión de subvenciones a entidades de iniciativa social sin ánimo de lucro para acciones dirigidas a la realización de proyectos de integración y se aprueba la convocatoria, mediante tramitación anticipada, de dichas subvenciones para la realización de proyectos de integración en los años 2008 y 2009. 
ras y límites acumulados, o con problemas degenerativos ${ }^{27} \mathrm{y} / \mathrm{o}$ con deterioro físico o emocional ${ }^{28}$. Se va definiendo así la exclusión social como algo individual que responde a situaciones intensas y/o graves, de extrema necesidad, enfermedad o pobreza absoluta. Consecuentemente, se enfatiza la utilidad y la necesidad de la RMI en cuanto prestación económica que pretende dar cobertura a las necesidades de «los más excluidos» (Ley 17/2001: 17), es decir, de las personas que carecen de recursos económicos para hacer frente a las exigencias básicas de la vida ${ }^{29}$ (Ley 17/2001: 17). En congruencia con ello, la Dirección General de Servicios Sociales de la Comunidad de Madrid, cuando describe su actuación en materia de garantía de ingresos, asegura lo siguiente:

«El objetivo general es mejorar la política de protección económica para poder dar cobertura a los hogares en situación de pobreza extrema en la Comunidad de Madrid, haciendo también hincapié en la intensidad de las situaciones de exclusión» ${ }^{30}$.

Así, la RMI no ha sido concebida para aquellas situaciones que no sean de gravedad o no se correspondan con una situación de pobreza extrema ${ }^{31}$. Fassin ${ }^{32}$ analiza cómo se distribuyen los subsidios a los desempleados en

${ }^{27}$ L. Nogués y A. Rodríguez, «El acompañamiento social de familias gitanas con trayectorias de marginación y exclusión residencial», Revista de Documentación Social, núm. 145 (2007), pp. 133-152.

${ }^{28}$ C. FERNÁNDEZ y P. TAPIA, «Los itinerarios de inserción social y el trabajo en red», incluido en el material del curso «La integración social en la Comunidad de Madrid: el Plan Regional contra la Exclusión Social», organizado por el Instituto Madrileño de Administración Pública (IMAP) y por la Consejería de Familia y Asuntos Sociales (Dirección General de Voluntariado y Promoción Social), 2007, pp. 195-266.

${ }_{29}$ En este sentido llama la atención cómo la renta mínima, en cuanto a su naturaleza jurídica se refiere, tiene «carácter alimenticio en beneficio de todos los miembros de la unidad de convivencia».

30 Disponible en http://www.madrid.org/cs/Satellite?c=PageEcid=1109266100977\&id Consejeria $=1109266187278 \varepsilon i d$ ListConsj $=1109265444710$ EidOrganismo=1109266227679 Epagename=ComunidadMadrid\%2FEstructuraEsm $=1109266100977$.

31 Llama la atención que en las «Jornadas para la Inclusión Social», organizadas por la Fundación Luis Vives y por el Departamento de Rentas Mínimas de la CM, se proyectara el video En el umbral (2006), de la directora Pepa G. Ramos. Fue utilizado como herramienta para debatir sobre cómo la exclusión social afecta en la Unión Europea a muchas personas asalariadas, quienes son despedidas continuamente por el excedente de mano de obra capacitada. De este modo, desde la misma institución que suscribe una ley con un significado restringido de la exclusión social se organizan talleres y seminarios en los que se ofrecen visiones más complejas del fenómeno.

32 D. FASSIN, «Gobernar por los cuerpos, políticas de reconocimiento hacia los pobres y los inmigrantes en Francia», Cuadernos de Antropología Social, núm. 17 (2003), pp. 54-55. 
Francia o las tarjetas de residencia a los inmigrantes que demuestran enfermedad y sostiene que «es el cuerpo el que da derecho, a título de enfermedad o de sufrimiento»; sin embargo, en el caso de la RMI, es el aspecto a la vez carencial y grave el que otorga legitimidad a los solicitantes de la prestación económica. Por tanto, parafraseando a Fassin se podría decir que, estrictamente hablando, no es el cuerpo el que da derecho a la prestación, sino el cuerpo que sufre visiblemente y que tiene carencias graves:

«Las reglas de justicia aparecen como normas con miras a atribuir recursos en función de criterios neutros: suma disponible por persona, composición del hogar, demandas particulares [...]. Sin embargo, esos mismos criterios reposan sobre el reconocimiento de seres cuyo infortunio extremo justifica una medida que debe aparecer a la vez como urgente, indispensable y específica: la ley habla de "desamparo grave" para los fondos de emergencia social, de una "gravedad excepcional para la tarjeta de residencia" ${ }^{33}$.

En suma, no solo los excluidos se representan como gravemente afectados por diversas carencias y problemas, sino que prima una visión de la exclusión social como una «incapacidad» que les aflige, lo cual no les permite poder «salir de su situación por sus propios medios» o hacer frente a sus obligaciones ${ }^{34}$. Esta concepción se maneja tanto en las investigaciones que sirvieron de base para la elaboración del Plan contra la Exclusión de la Comunidad de Madrid ${ }^{35}$ como en los discursos de algunos trabajadores sociales entrevistados:

«No puede concebirse la incorporación social solo como acceso al empleo y a unos ingresos básicos. Se trata de una situación de la que no se puede salir sin apoyos, marcada por una dinámica de irreversibilidad al menos a corto plazo y por esa cierta incapacidad de las personas afectadas de salir de su situación por sus propios medios» ${ }^{36}$.

Así, se va configurando una determinada imagen del sujeto al que la RMI pretende dar cobertura: el que «queriendo y no pudiendo trabajar

33 Ibid., p. 68.

${ }^{34}$ E. M. JuAn, «La respuesta de los servicios sociales ante los procesos de exclusión social: historia de tres mujeres», Revista de Servicios Sociales y Politica Social, núm. 81 (2008), p. 95.

${ }_{35}$ M. Aguilar, M. Laparra y B. Pérez, La exclusión multidimensional en el espacio urbano: investigaciones de base para la elaboración del Plan contra la Exclusión de la Comunidad de Madrid, Universidad Pública de Navarra y Consejería de Servicios sociales de la Comunidad de Madrid, 2003.

36 Ibid. 
por la situación de exclusión social en que se encuentra, está situado en la marginalidad y la pobreza» ${ }^{37}$. El excluido es el que tiene múltiples problemas y carece de herramientas o de habilidades para afrontarlos:

«Para mí, la exclusión es la dificultad para ver horizontes. Es una persona que no tiene herramientas ni referentes donde [...]. Para mí un excluido es el que tiene las posibilidades de cambio muy reducidas y el horizonte muy pequeño de mejora de condiciones de vida, de mejora de bienestar personal, de satisfacción. Es mucho más que lo económico» (entrevista a trabajadora de servicios sociales, zona centro de Madrid, cuarenta y cinco años).

Por tanto, la RMI se define como una política social dirigida a personas «en estado de exclusión social»; una especie de estado estático del que estas personas quieren pero «no pueden salir», enalteciéndose así el poder de la voluntad (el querer) como cualidad moral necesaria para «mejorar» ${ }^{38}$ :

«[La ley] responde a un afán decidido del gobierno regional de ir extendiendo el ámbito de su política social hacia sectores cuyas necesidades no están todavía suficientemente protegidas, consciente de que la sociedad madrileña solo alcanzará las cotas de bienestar social a las que es acreedora si se avanza hacia la consecución de un progresivo equilibrio entre los distintos sectores que la forman, para lo cual se hace indispensable satisfacer las necesidades de quienes no pueden salir de la situación de exclusión social en que se encuentran» (Ley 15/2001: 11).

En suma, la Ley 15/2001 se refiere a personas con problemas individuales y carencias graves que «no pueden salir» de la situación de exclusión social en la que se encuentran, siendo estas, en última instancia, las acreedoras legítimas de la prestación. A este respecto, Castel $^{39}$ ha advertido del peligro de autonomizar las situaciones límites y de convertir la exclusión social en un estado que habría que tratar de subsanar en sí mismo. Pero una vez que se ha definido en estos términos, los profesiona-

${ }^{37}$ J. M. Alonso, «Nuevos derechos en la Comunidad de Madrid para las personas socialmente excluidas...», op. cit., p. 186.

38 A. Franzé y D. Parajuá, «Políticas públicas, migración y redefinición de sujetos en contextos de vulnerabilidad», en V Congreso REPS (Red Española de Política Social). Desigualdad y democracia: políticas públicas e innovación social, Barcelona, Institut de Govern i Polítiques Públiques (IGOP-UAB), 2015.

39 R. CASTEL, La metamorfosis de la cuestión social: una crónica del salariado, Buenos Aires, Paidós, 1997, p. 28. 
les de la intervención social entran en escena y son vistos como los encargados de apoyar a dichas personas para que logren salir de la situación de exclusión. Lo anterior, obviamente, es difícil de conseguir sin el interés de «los excluidos» por cambiar, presuponiéndose así en ellos una actitud que tienen que mostrar para poder ser ayudados.

La tendencia a situar en el individuo las causas de la exclusión social es coherente con los instrumentos para la inserción social que se derivan de la RMI (PII, programación de acciones individualizadas para cada persona, seguimiento individualizado de las mismas, etc.), diseñados de una forma que «se adaptan» a cada caso personal. El riesgo de individualización del conflicto social a través de instrumentos de intervención social como el «contrato» ${ }^{40}$ ha sido puesto de manifiesto por autores como García García ${ }^{41}$ o Castel $^{42}$; instrumentos que se entienden como herramientas para afrontar y solucionar las múltiples «carencias» de las personas a las que van dirigidos:

«El PII es una previsión de acciones cuya finalidad es evitar procesos de exclusión personal, social y laboral, y contribuir a la inserción social de quienes "carezcan" de los recursos personales o sociales suficientes para desarrollar una vida independiente» (Decreto 147/2002: 56).

\section{Los profesionales como «activadores» de los sujetos en situación de exclusión social}

La labor de los profesionales se define en diversos textos como consistente en averiguar las demandas o deseos de cambio latentes en la persona excluida ${ }^{43}$. De este modo, el sujeto excluido, a la vez que como deteriorado, es concebido como multiproblemático y aquejado de toda una serie de carencias psicoafectivas, como alguien que quiere cambiar pero que no puede, siendo el profesional el encargado de «ponerse en contacto directo con los sentimientos y ansiedades de la persona» ${ }^{44} \mathrm{y}$ de ser un «foco que va

${ }^{40}$ M. Foucault, «La gubernamentalidad», en M. Foucault et al., Espacios de poder, Madrid, La Piqueta, 1981 [1978], p. 20, sostiene que la teoría del contrato es la matriz teórica de un específico arte de gobierno.

${ }^{41}$ S. GarCía GarCÍA, «Hermenéutica de la queja...», op. cit.

${ }^{42}$ R. CASTEL, La metamorfosis de la cuestión social... op. cit.

${ }^{43}$ L. Nogués y A. Rodríguez, A., «El acompañamiento social de familias gitanas...», op. cit., y C. FERNÁNDEZ y P. TAPIA, «Los itinerarios de inserción social...», op. cit.

${ }^{44}$ C. Fernández y P. TAPIA, «Los itinerarios de inserción social...», op. cit., p. 200. 
poniendo luz a lo que la persona o familia va iluminando a su vez» ${ }^{45}$. Así, desde una perspectiva que pretende hacer a la persona excluida protagonista de su propia vida, los profesionales quieren contribuir a encontrar los objetivos — supuestamente- perseguidos por los sujetos excluidos. Esto quiere decir que se están usando concepciones contradictorias de estos, que pasan de atribuirles una situación de ansiedad y de multiproblematicidad a considerar que disponen de una motivación escondida o latente para desear un cambio propio y personal. Esta ambigüedad a la hora de definir a la persona excluida es un mecanismo retórico que conviene y legitima la intervención profesional, que a partir de ese momento se articula como el dispositivo encargado de despertar la motivación o el deseo que esa persona, a pesar de las dificultades para expresarlo, tendría. La intervención queda materializada en un proceso de inserción social «adaptado» a las demandas, capacidades, habilidades y «potencialidades personales» de los sujetos $^{46}$, y los profesionales se entienden como los encargados de «sacar» a estas personas de la situación en la que se encuentran, movilizando sus capacidades internas, así como su motivación subyacente o escondida:

«El problema es que la exclusión social tiene muchos ámbitos de actuación. No solo concierne al empleo o a la familia o a cualquier tipo de situación que le pueda conllevar a una persona estar en una situación que no está bien vista por la sociedad o que se encuentra con una necesidad que hace que tenga un problema. No se puede decir: "Vamos a trabajar con formación para el empleo". Vale, ese puede ser un recurso bueno para sacar a una parte de personas que pueden estar en situación de exclusión social» (entrevista a técnico de la CM, treinta y siete años).

Las diferentes representaciones que se manejan de los sujetos excluidos sitúan a los profesionales en relaciones jerárquicas también diferentes con respecto a ellos. Así, en caso de conceptualizarse al excluido como multiproblemático y al profesional como quien puede «ayudarle» a salir del

${ }^{45}$ Ibid., p. 223. M. Gullestad, Picturing Pity. Pitfalls and Pleasures in Cross-Cultural Communication. Image and Word in a North Cameroon Mission, New York-Oxford, Berghahn Books, 2007, en un interesante análisis de la documentación escrita y visual producida por los misioneros noruegos, ha estudiado las metáforas que utilizaron sobre la oscuridad de los africanos a los que iban a dotar de «luz» mediante la educación dada en las misiones que establecieron en Camerún y la jerarquía y el paternalismo que guiaban sus actividades. La representación sobre la carencia educativa de los africanos legitima la actividad social de los misioneros, sin cuestionar en ningún momento los efectos más amplios que se derivan de sus acciones ni las contradicciones y tensiones inherentes a las mismas.

46 C. FernándeZ y P. TAPIA, «Los itinerarios de inserción social...», op. cit., p. 235. 
estado de exclusión social en el que se encuentra, la superioridad que se le otorga a este último es patente ${ }^{47}$. Gullestad ${ }^{48}$ plantea que la «bondad» de la intervención profesional no se cuestiona y siempre necesita la generación de un «otro» necesitado y poco evolucionado al que hay que asistir. Por ello resulta sorprendente que, en el caso de la RMI, después de haber dibujado al excluido como una persona con serias discapacidades sociales y personales, se pase a definir la intervención social en términos igualitarios y se afirme que el profesional y el sujeto excluido establecerán los objetivos de inserción «coparticipadamente», como si ambos estuviesen situados en posiciones sociales parejas. A continuación se le asignan al segundo características como la autonomía, la capacidad de discernimiento y análisis sobre su propia situación, a la vez que la aptitud para diseñar él mismo, en coparticipación con los profesionales, los objetivos de su PII. Agudo ${ }^{49}$ ha indicado que la palabra «coparticipación» se utiliza frecuentemente como una metáfora movilizadora en el mundo de las políticas sociales ${ }^{50}$ :

«La tarea del profesional será categorizar y establecer conexiones hipotéticas entre los datos que nos suministra el cliente para así dar nueva luz al problema y acercarnos al cambio deseado por ambos» ${ }^{51}$.

El profesional, situado así en el mismo nivel que el excluido y dispuesto a establecer una «coparticipación» o negociación (obviando las diferentes

${ }^{47}$ M. Aznar, «Tres reflexiones en torno a la Renta Mínima de Inserción», El Boletín del CEBS, núm. 26 (1991), sugiere que los mecanismos de contractualización vinculados a la RMI corren el riesgo de poder convertirse en una forma novedosa de legitimación de un modelo asimétrico de implementación del trabajo social.

${ }^{48}$ M. Gullestad, Picturing Pity. Pitfalls and Pleasures..., op. cit.

49 A. AgUdo, «Conocimiento, lenguaje, poder e intermediación. Perspectivas contemporáneas en la antropología de las políticas públicas», Estudios Sociológicos, vol. 27, núm. 79 (2009).

${ }^{50} \mathrm{La}$ coparticipación puede ser vista como una palabra clave dentro del discurso de las políticas sociales (vid. R. Williams, Keywords, London, Fontana, 1983, y A. Agudo, «Conocimiento, lenguaje, poder e intermediación...», op. cit., p. 71). Las palabras como esta son agradables, persuasivas, políticamente correctas o, más bien, neutras, pues todos estamos de acuerdo acerca de ellas y todos las usamos. Entre ellas, además de «coparticipación», están palabras como «comunidad», «familia», «corresponsabilidad» y «cooperación». Cuando resultan exitosas en disputas dentro del ámbito de lo político y atraen un apoyo generalizado podemos denominarlas «metáforas movilizadoras» [vid. C. SHore y S. WRight (eds.), Anthropology of Policy: Critical Perspectives on Governance and Power, London-New York, Routledge, 1997, pp. 19-20], que son fundamentales en las «grandes narrativas del desarrollo social» (D. Mosse, Cultivating Development. An Ethnography of Aid Policy and Practice, London, Pluto Press, 2005, pp. 8-9).

${ }_{51}$ A. Rodríguez y T. Zamanillo, «Apuntes para una valoración diagnóstica», RTS: Revista de Treball Social, núm. 127 (1992), p. 50. 
condiciones sociales y materiales de existencia y la definición inferiorizante que se ha dado previamente del sujeto excluido), orienta su intervención social a establecer un vínculo de confianza con el usuario que sirva para concretar las «demandas expresadas y las expectativas depositadas por la persona en el profesional y la institución ${ }^{52}$. No aparece, en los textos consultados, ninguna duda sobre esa milagrosa coincidencia de expectativas entre los profesionales y los sujetos excluidos.

Encontramos, en los discursos de la mayoría de los profesionales entrevistados, una concepción de la intervención social que se centra, por un lado, en movilizar al sujeto excluido, como si se encontrase — como se ha subrayado- en una especie de estado estático del que hay que ayudarle a salir y, por otro, en una consideración de este como contraparte que ha de participar activamente en su propio cambio personal. En la figura 4 se presenta esquemáticamente la relación que, desde la perspectiva de los trabajadores sociales que intervienen con la RMI, se establece entre exclusión social e intervención profesional.

De la intervención profesional se espera que coadyuve a la integración, apareciendo la inserción laboral como condición necesaria para que los sujetos excluidos consigan características tales como la autonomía, la independencia y la libertad:

«Con los hijos, el objetivo era que empezaran a... (titubea), ¡a ver cómo lo digo!, que empezaran a desear trabajar, o sea, que empezaran a ver que en el trabajo existen más oportunidades, o sea, la oportunidad de ser más autónomos y más independientes y más libres que no en la RMI, que no en la dependencia de las instituciones, sea del tipo que sea. Ese era el objetivo. Para eso a lo mejor había que empezar con unos talleres prelaborales de no sé qué o con unas habilidades sociales... Con los padres que apoyaran eso, que los hijos entraran en algún tipo de formación o proceso ya de búsqueda, porque había situaciones distintas, para que el futuro de sus hijos no fuera el de ellos» (entrevista a extrabajadora de servicios sociales en mancomunidad madrileña, treinta y siete años).

Esta visión de la integración social a través del empleo es la misma que promueven la ley y el decreto de la RMI y se inserta dentro de un marco de políticas sociales neoliberales en el que los mecanismos de mercado se perciben como los más adecuados para el progreso y la activación social ${ }^{53}$.

52 C. FernándeZ y P. TAPIA, «Los itinerarios de inserción social...», op. cit., p. 233.

53 D. Ávila y M. Malo, «Manos invisibles...», op. cit. 
FIGURA 4

Resumen esquemático de la relación entre la definición de exclusión social y la conceptualización de la intervención social

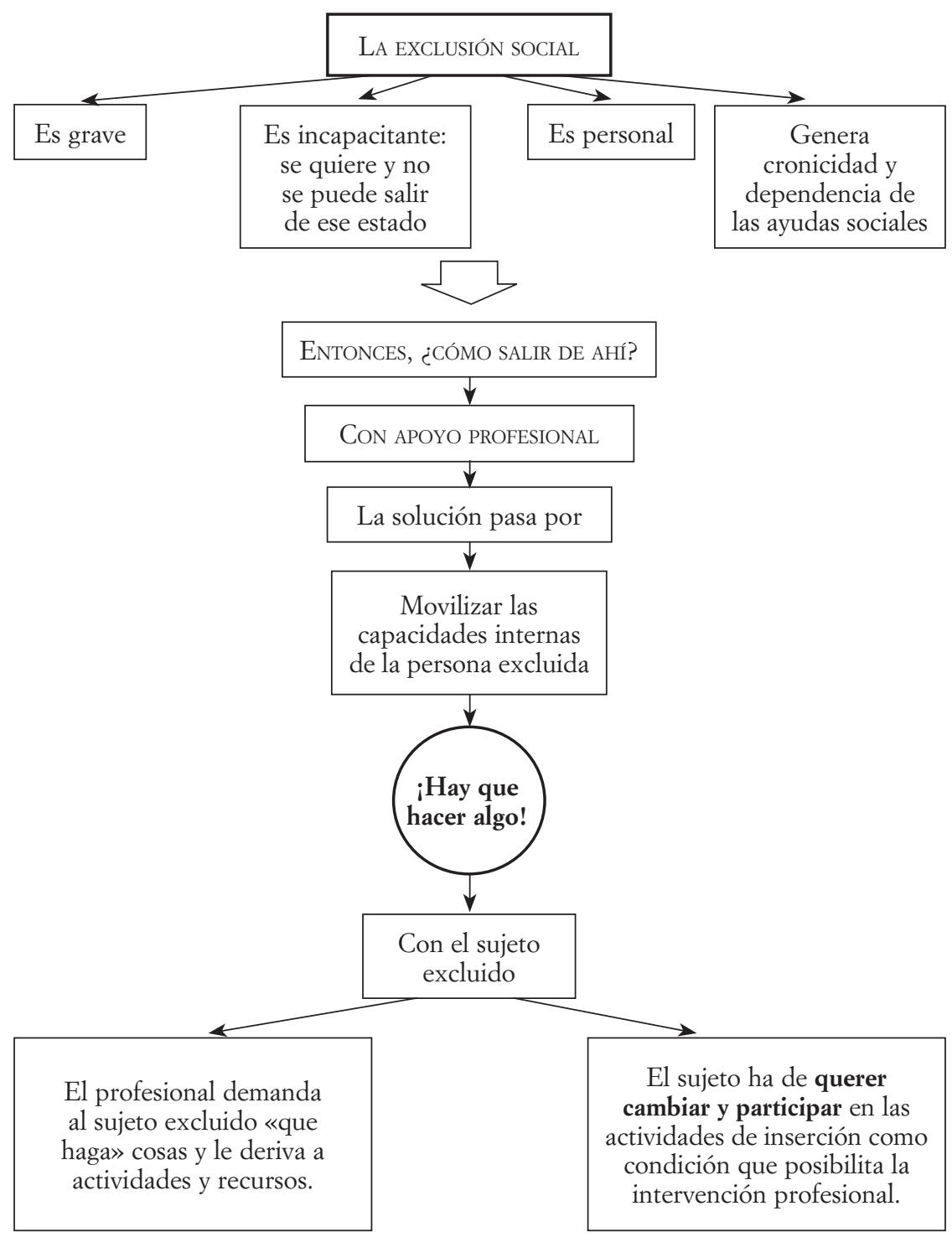

Fuente: Elaboración propia. 
«Lejos de concebirse como una prestación asistencial pasiva, lo que se pretende con ella es eliminar las causas que puedan conducir a una exclusión progresiva, con el fin último de que la persona que la recibe, así como los miembros de su unidad de convivencia, encuentren ese empleo adecuado que les conduzca a una realización personal y social [...]. En el supuesto de perceptores de la renta mínima de inserción se iniciará un programa de duración semestral que incluya el diagnostico de su situación social y las medidas más eficaces para conseguir su incorporación laboral» (Decreto 147/2002).

El análisis de los documentos reguladores de la prestación IMI y de la RMI muestra que la integración social aparece conceptualizada en términos de un proceso lineal de evolución que comienza con la detección de la persona con problemas, el «diagnóstico» de su situación social y el establecimiento de medidas/acciones de cumplimiento personal, y finaliza con la inserción laboral, que conduciría ineludiblemente a la salida de la situación de exclusión material y a la consecución de la realización personal y la cohesión social:

«No se reduce a una concepción simplista de la integración por el dinero. Al contrario, la prestación económica se concibe al servicio de todo un profundo proceso de integración, que deberá ser definido a nivel individual y adaptado a las necesidades y peculiaridades de cada persona y de cada entorno social» (Decreto 73/1990).

García García ${ }^{54}$ ha señalado la similitud entre el modelo de atención de los servicios sociales y el de atención sanitaria en cuanto a la secuencia lógico-deductiva que va de lo general a lo específico, esquema cognitivo procedente del discurso científico que se materializa en el itinerario de atención. Este autor sostiene que la influencia positivista y neopositivista ha estado presente en el trabajo social en Occidente de manera muy marcada, haciendo referencia a la ideología del «progreso», definida como el propósito de proyección de cambios hacia el futuro:

«Esto convierte al trabajo social en una tecnología que aplica, generalmente prescindiendo de la subjetividad de las personas con las que trabajamos, diseños de intervención social, objetivos generales, objetivos específicos, presuponiendo una secuencialidad lógica y deseada de nuestras proyecciones y nuestras acciones» ${ }^{55}$.

\footnotetext{
${ }^{54}$ S. GarCía GarCía, «Hermenéutica de la queja...», op. cit.

55 Ibid.
} 
A su vez, esta concepción unilineal del progreso iría unida a la visión del conocimiento como verdad única que promueve el control sobre el entorno ${ }^{56}$. En este sentido, Arendt ${ }^{57}$ aborda la creencia decimonónica en el progreso como una de las supersticiones más complejas de nuestra época. La noción de que existiera algo semejante a un progreso de la humanidad en su totalidad era desconocida antes del siglo XVII, pero desde entonces cambió hasta transformarse en opinión corriente entre los hombres de letras del siglo XVIII y se convirtió en un dogma casi universalmente aceptado durante el siglo XIX. Pero la diferencia entre las primeras nociones del progreso y la de su última fase es decisiva. En el siglo XVII, representado especialmente por Pascal y Fontenelle, se pensaba en el progreso como en una acumulación de conocimientos a través de los siglos, mientras que en el siglo XVIII la palabra implicaba una «educación de la humanidad». Así, el perfeccionamiento humano a través de la educación supone la posibilidad de mejoras futuras, dotando a la noción de progreso de un nuevo sentido temporal (futuro concebido siempre como una mejora de la situación presente). A partir de este momento, el movimiento adquiere un significado central en la noción de progreso.

Arendt ${ }^{58}$ hace referencia a una idea de Proudhon que ha resultado ser muy esclarecedora para analizar los discursos referentes a la exclusión social provenientes de los profesionales, esto es, para apreciar que a partir del siglo XIX es la propia idea del movimiento la que se vuelve esencial en el concepto de progreso. Este movimiento no tiene ni principio ni fin, y lo importante es el movimiento en sí. La autora sostiene que la perpetua continuidad del progreso tiene que ver con algunas de las ventajas asociadas a su «creencia», pues esta apunta a un continuum de tiempo lineal y un constante progreso en la historia. De este modo, la tranquilizadora idea de que «solo necesitamos marchar hacia el futuro» ofrece la posibilidad de explicar el pasado sin romper el continuum temporal y sirve también como guía de actuación en el futuro. Además, aporta la seguridad de que no puede suceder nada nuevo y totalmente inesperado, nada que no sean los resultados «necesarios» de lo que ya conocemos ${ }^{59}$.

En congruencia con lo anterior, ante la pregunta ¿qué hacer con las personas en situación de exclusión social?, es común que los profesionales hagan referencia a la idea de movimiento como elemento que garantiza «el

\footnotetext{
56 Ibid.

57 H. ARendt, Sobre la violencia, Madrid, Alianza Editorial, 2005 [1969], pp. 44-45.

58 Ibid., p. 41.

59 Ibid., p. 43.
} 
avance» de estas personas. Así, parece que hubiese que «activar» a las personas en situación de exclusión social y que la consecución de movimiento fuese, en sí misma, condición para la integración social:

«Porque la primera pregunta es "¿está usted conforme con su vida así?”. Porque, además de dinero, qué más cosas quiere hacer, porque yo creo que lo primero que hay que hacer es entrar en una dinámica de ver en qué medida uno está satisfecho, está a gusto. No está a gusto porque no tiene dinero pero algo más... Quiero decir, tienes que entrar en una dinámica de intervención, no en una dinámica de: "¿Qué es lo que pide usted?", o "Yo creo que usted, además del dinero, usted lo que tiene que hacer es un curso de jardinería". "¿Pero tiene habilidades o intereses? ¿O está en esa...?”. Porque a lo mejor lo que hay que mandarle es a un proyecto que le dinamice mínimamente o que le ayude a ver qué más tiene que hacer para encontrarse incómodo con la situación en la que está. No sé cómo decirte: activarle desde otra óptica. Que trabajen [en los proyectos de integración] mucho más procesos de desarrollo personal, procesos de habilidades muy básicas, de activación como ciudadanos de...» (entrevista a técnica de la CM, cincuenta años).

Igualmente, se considera que el movimiento hacia la «evolución» que está experimentando parte del colectivo gitano (especialmente las mujeres) es imparable:

«En unas jornadas para presentar un libro con el resumen de un proyecto de varias ONGs de promoción de la mujer gitana en abril de 2008 hablan las representantes del Ayuntamiento para animar a las mujeres a que sigan formándose. La representante de la Mesa de Igualdad Asunción Miura, conocida del movimiento feminista proigualdad de Madrid, dice algo así como: "Las mujeres gitanas habéis entrado en un camino que no tiene marcha atrás. Gitanas o payas somos mujeres que tenemos que ir hombro con hombro". La directora de una ONG añade: "Queremos que os insertéis, no podemos poneros un caramelo en la boca y luego quitároslo"» (registro de campo: observación participante en la presentación del libro Artemisas, abril de 2008).

A este respecto, en los discursos de los profesionales se detecta una diferencia sobre qué pedir a las personas excluidas. En cuanto a aquellas que se consideran realmente necesitadas e incapacitadas para insertarse a través del mercado laboral y que no cuestionan los valores de autonomía, formación y empleo que los profesionales quieren que hagan suyos, no importa 
que «no hagan nada» o que únicamente asistan de vez en cuando a alguna actividad para la inserción social. En estos casos, basta con la participación social; apareciendo la idea de que esta es el medio para la cohesión social y la configuración de los sujetos excluidos como ciudadanos. De este modo, el trabajo de las ONGs consiste en construir para «su clientela» espacios de sociabilidad diferentes de aquellos en los que vive para hacer soportable una cotidianidad desesperante ${ }^{60}$. En términos de Berger y Luckman ${ }^{61}$, se puede decir que este tipo de actividades de inserción intenta una «socialización secundaria» consistente en «vincular al individuo con un submundo institucional o basado en instituciones». En cambio, a las personas excluidas a las que no se percibe como física o psíquicamente incapacitadas para acceder al empleo se les pide que se conduzcan como sujetos autónomos y que construyan, en términos reflexivos y con apoyo profesional, un proyecto personal y profesional, un «itinerario de vida». De esta manera se cumple la «matriz contractual» señalada por Castel ${ }^{62}$ a partir de su análisis de las políticas de inserción en Francia, según la cual a los individuos más desestabilizados se les exige que se comporten de un modo improbable incluso entre «población normalizada» (como es hacerlo como «sujetos autónomos»). En el contexto español, la Fundación Luis Vives (2008), en un texto de síntesis de varios encuentros profesionales, indica que se suele acabar «desprotegiendo», a través de la demanda de contraprestaciones, a quienes están menos preparados para incorporarse sociolaboralmente.

Por otra parte, con los usuarios de la RMI «que pueden» pero no demuestran tener la voluntad para trabajar o para establecer el mencionado proyecto vital de ascenso social, se despliegan las estrategias profesionales más insistentes para promover que «hagan algo». En relación con ello, algunos autores han sugerido que la incomodidad que sienten los profesionales con respecto a estos usuarios «problemáticos» responde a una toma de conciencia de la inexistencia de actividades orientadas a la integración que sean adecuadas para ellos, revelando las carencias de los servicios sociales ${ }^{63}$ :

«Es que la definición de exclusión es compleja. O sea, yo creo que en estos casos [población gitana] no es la exclusión del que no puede, sino

${ }^{60}$ R. CASTEL, La metamorfosis de la cuestión social... op. cit., p. 437.

${ }_{61}$ P. Berger y T. Luckmann, La construcción social de la realidad, Buenos Aires, Amorrortu, 1989, y R. CASTEL, La metamorfosis de la cuestión social..., op. cit., p. 437.

62 R. CASTel, La metamorfosis de la cuestión social... op. cit., p. 474.

${ }_{63}$ M. Aguilar, M. Gaviria y M. Laparra, El Programa Ingreso Madrileño de Integración..., op. cit., pp. 137-138. 
del que se encuentra incapacitado para aprovechar oportunidades. ¿Sabes lo que pasa? Que tú trabajas con otra gente y dices: "Este tío está en la puta calle [sin techo] y este otro tío [gitano] está desaprovechando las oportunidades que tiene y que desde el sistema se le brindan"» (entrevista a trabajador de servicios sociales, zona sureste de Madrid, treinta y ocho años).

Por el camino, las nociones de integración, de inserción, de incorporación y/o de inclusión social aparecen sin definir, sustituyéndose las unas a las otras y siendo difícil encontrar estudios que reflexionen sobre los matices diferenciales que introducen estas expresiones ${ }^{64}$. En esta línea, autores como Autès ${ }^{65}$ y Agudo ${ }^{66}$ advierten que nuevas categorías de la acción pública han penetrado desde hace algunos años en las políticas sociales, entre ellas las de inserción o participación. Y Martínez Román ${ }^{67}$, después de realizar una revisión bibliográfica para ver el sentido y la utilización de los términos «integración» e «inserción», señala que, aunque se usan indistintamente como si fueran sinónimos, hay una preferencia por el de «inserción»:

«A causa de la existencia de un rechazo del término "integración", adjudicándole connotaciones negativas relacionadas con tentativas de asimilación y homogeneización de las personas con dificultades a partir de un cierto modelo implícito basado en la población considerada "normal" ${ }^{68}$.

Esta puede ser una de las razones por las que, en algunos textos como el de Renes y Lorenzo ${ }^{69}$, se opta por sustituir la palabra integración por las de inclusión, incorporación o inserción, indistintamente. Por su lado, Demazière y Dubar $^{70}$ se refieren al «bricolaje intelectual» que supone la noción

${ }^{64}$ V. RENES y F. LoREnZO, Cuestiones y retos clave en la inclusión social. Documento provisional para debate 1, Madrid, Fundación Luis Vives, 2007, p. 19. En este trabajo elaborado por Renes y Lorenzo para la Fundación Luis Vives y financiado por la Comisión Europea a través del Programa Comunitario de Acción para Combatir la Exclusión Social 2002-2006 se puede ver una combinación interesante de los términos inclusión, incorporación e integración social, sin que aparezca algún matiz que permita diferenciarlos.

${ }_{65}$ M. AutĖs, «Tres formas de desligadura», en S. KARSz, La exclusión social: bordeando sus fronteras. Definiciones y matices, Barcelona, Gedisa, 2004, p. 20.

66 A. Agudo, «Conocimiento, lenguaje, poder e intermediación...», op. cit., p. 91.

${ }_{67}$ M. A. Martínez Román, «Género, pobreza y exclusión...», op. cit., p. 76.

${ }^{68}$ Ibid.

${ }^{69}$ V. RENES y F. LORENZO, Cuestiones y retos clave en la inclusión social..., op. cit.

70 D. Demazière y C. Dubar, Analyser les entretiens biographiques: l'exemple des récits d'insertion, Paris, Nathan, 1997. 
de inserción y Zamanillo ${ }^{71}$ sostiene que los trabajadores de servicios sociales han de ampliar y matizar el concepto que utilizan de integración. Para Murard $^{72}$, este término, si bien no aporta gran cosa en el plano teórico, sí permite interpelar a los trabajadores sociales, quienes deben favorecer «la inserción social» en detrimento de la «inserción profesional», promoviendo una «economía solidaria» que permita no solamente integrar a los excluidos, sino también ofrecer una alternativa al mercado ${ }^{73}$.

En los programas de rentas mínimas, la inserción aparece siempre asociada a la participación en distintas actividades que se supone que sirven para integrar a los beneficiarios de prestaciones sociales como la RMI. Así, es común la utilización del término inserción como parte del acervo profesional «técnico» o «experto», haciendo referencia a un paso necesario en el camino hacia la integración, tal como se ha indicado ya antes. De nuevo, aparece de forma implícita una suerte de esquema evolutivo según el cual se comenzaría por encontrar empleo (inserción laboral) y se terminaría por estar «integrado» socialmente.

Por otro lado, encontramos una división de los usuarios de los programas de rentas mínimas basada en las expectativas que se tienen de sus capacidades. Así, los «empleables» son redirigidos a actividades formativas conducentes a la incorporación al mercado laboral, y con los casos «perdidos» (para la «verdadera integración», que se consigue a través de la inserción laboral) se busca trabajar sus habilidades sociales en la línea de grupos de autoayuda o de establecimiento de relaciones sociales que suban la «autoestima» (de manera congruente con la lógica de la activación). Como ya se indicó, Martínez Román ${ }^{74}$ se pregunta si esta concepción de la inserción no ha generado una segunda categoría de ciudadanos: la de aquellos no empleables para los que, por ello, se idean diferentes «dispositivos de inserción» a fin de mantenerlos ocupados.

Así, debido a que los profesionales de servicios sociales estiman que los gitanos tienen capacidades suficientes para que, con esfuerzo, tesón y motivación, puedan formarse e integrarse al mercado laboral formal, no son

71 T. Zamanillo (coord.), Análisis diagnóstico de la investigación-acción con profesionales que realizan el acompañamiento social a beneficiarios de la RMI, Convenio entre la Consejería de Servicios Sociales y la Universidad Complutense de Madrid, documento mimeografiado, 2004, p. 61.

72 N. MuraRd, La morale de la question sociale, Paris, La Dispute, 2003, p. 108.

73 Traducción propia de los términos usados por el autor. Se detecta un paralelismo entre el desdoble de la categoría de inserción (entre inserción profesional e inserción social) y la distinción realizada por H. ARENDT, Sobre la violencia, op. cit., entre trabajo y obra.

${ }^{74}$ M. A. MARTínez Román, «Género, pobreza y exclusión...», op. cit., p. 78. 
considerados como candidatos adecuados para las actividades vinculadas al ocio o al establecimiento de relaciones sociales, dirigidas principalmente a los colectivos «no empleables» ${ }^{75}$. La «falta de motivación» del colectivo gitano o su negativa a participar en ciertas acciones propuestas por los profesionales son interpretadas por estos como afrentas al criterio profesional y como rechazos a su integración, de ahí la representación del gitano — que se cuela por todos lados- como resistente al cambio, poco motivado, que utiliza los recursos y las ayudas que le interesan sin dar mucho a cambio.

\section{La importancia del «hacer algo» como constitutivo del sujeto racional moderno}

A pesar de las diferencias que muestran en otros aspectos, todos los profesionales entrevistados coinciden, en consonancia con las subjetividades actuales que promueve el neoliberalismo en su forma social ${ }^{76}$, en dar gran importancia al hecho de que el sujeto excluido «se mueva» y «haga algo» como solución o mitigación de su situación de exclusión, de modo que les incomoda «el estatismo» de algunos beneficiarios de la RMI —entre ellos, los gitanos-, quienes no se entusiasman con la idea de tener que construir en esos términos un proyecto individual de cambio. A este respecto se puede sugerir como hipótesis que los profesionales comparten una creencia sobre el sujeto como actor libre de su destino, que va acompañada del enaltecimiento de valores como la disciplina, la autonomía, el esfuerzo, el ascetismo, la educación reglada, a la vez que de la percepción/ asunción de que la racionalización y la planificación (con lo que estos procesos conllevan de internalización y control del tiempo) son elementos básicos para la «integración» del sujeto a la sociedad. La capacidad de los profesionales para lograr que los perceptores de la RMI se movilicen dota de reconocimiento y legitimidad a su labor profesional.

75 Si bien los cursos a los que asisten las mujeres gitanas suelen estar legitimados, por parte de los trabajadores de servicios sociales, como actividades que promueven la participación social en un cierto sentido, esto es, como rutinas de socialización que generan «red social», los profesores de dichos cursos consideran que las mujeres han de mejorar su nivel lecto-escritor y aprender unos «mínimos» (como hacer un curriculum vitae o utilizar tranquilamente las instituciones públicas siguiendo sus normas internas) de cara a buscar un empleo. De este modo, se comportan como si estos cursos fuesen un paso previo a la inserción laboral.

76 C. Laval y P. DaRdot, La nueva razón del mundo. Ensayo sobre la sociedad neoliberal, Barcelona, Gedisa, 2013. 
Nos encontramos de nuevo con la individualización de la cuestión social y el resurgimiento de una evaluación de comportamientos individuales cuando las instituciones se hacen cargo de las situaciones de vulnerabilidad ${ }^{77}$. Con todo, la conminación a la autonomía de los usuarios de los programas de la RMI por parte de las instituciones sociales es paradójica, por un lado, porque los primeros son materialmente incapaces de responder al mandato de ser autónomos y, por otro, porque la interiorización de las normas que manejan esas instituciones con respecto a la autonomía puede llevar a los sujetos a desvalorizarse a sí mismos y volver a entrar en una forma de dependencia. Para Duvoux ${ }^{78}$, el mandato o conminación a la autonomía ${ }^{79}$ pone el acento sobre el reconocimiento de la singularidad del individuo, del que se espera que reflexione sobre su conducta en los mismos términos que lo hace el profesional y que se anime voluntariamente, con asesoría profesional, a «moverse» por su propio pie. Así, concluye, el mandato a la autonomía está implícito en las políticas de inserción ${ }^{80}$.

Una interpretación plausible de la frecuencia con la que aparece la idea de movimiento en los discursos profesionales proviene de Van Zanten $^{81}$, quien afirma que las personas de clase media y alta, entre las que se encontrarían los trabajadores/as sociales, son más propensas a adoptar una posición distanciada, informada, estratégica y políticamente consciente con respecto a su experiencia social, a la vez que tienden a concebirse a sí mismas como poseedoras de capacidades estratégicas, autoras de su propia vida y capaces de luchar contra las presiones sociales y de alterar el rumbo de las experiencias individuales. Esta autora relaciona la generalización contemporánea de la reflexividad, por un lado, con el aumento del conocimiento y de la penetración de la ciencia en los dispositivos de control ideológico y, por otro, con el aumento de la percepción social de los riesgos (sociales e individuales) a raíz de la desaparición de las certezas científicas, tecnológicas y sociales que caracterizaban a la sociedad industrial ${ }^{82}$. Las clases medias y altas están más familiarizadas con los conocimientos que producen las ciencias sociales, son también aquellas que

77 P. Rosanvallon, Réflexions sus la question sociale. Repenser l'État-providence, Paris, Le Seuil, 1995.

${ }_{78}$ N. Duvoux, L'autonomie des assistés..., op. cit., p. 15.

79 El término que utiliza el autor en francés es «injonction à l'autonomie».

${ }^{80}$ Ibid., p. 17.

81 A. VAn ZANTEn, «Reflexividad y elección de la escuela por los padres de clase media en Francia», Revista de Antropología Social, vol. 16 (2007), p. 250.

${ }^{2}$ Vid. U. BecK, A. Giddens y S. Lash, Reflexive Modernization. Politics, Tradition and 
creen en el conocimiento como elemento del progreso social, han mantenido una relación más estrecha con los dispositivos de control ideológico, sobre todo con los dependientes del Estado (la escuela, las industrias culturales, el sector del trabajo social), y las que se atribuyen a sí mismas un papel central en la sociedad debido a su posesión de un elevado capital cultural ${ }^{83}$. Esto las hace ser más sensibles que otras clases sociales a los riesgos y a las consecuencias sociales de su propia acción y de la acción de las instituciones en las que participan.

Autores como Petersen ${ }^{84}$ recuerdan las críticas hechas por algunos investigadores sociales ${ }^{85}$ al concepto de actor racional como dueño de su propia biografía de acuerdo a cálculos de riesgo y oportunidad, que desarrollan Giddens y Beck, así como a la idea de modernidad manejada por estos, y echan en falta un análisis del rol que desempeñan los expertos en la administración de poblaciones y en la regulación de la identidad personal ${ }^{86}$. En este sentido, en los discursos de profesionales entrevistados aparece una hipervalorización del sujeto autoreflexivo y autónomo, de ahí que algunos de ellos consideren que su labor pasa por ayudar a la persona a que ella misma cuestione - en términos reflexivos- sus circunstancias.

Díaz de $\operatorname{Rada}^{87}$, pensando en la escuela, asegura que en la base del impulso universalista de las instituciones burocráticas se encuentra una visión instrumental de la enseñanza, que parte de una idea utilitaria de que la educación (o, en este caso, la intervención social) es un medio que los sujetos usan para cumplir con fines racionalmente definidos y universalmente reconocidos. El problema surge cuando los profesionales se encuentran con usuarios que no analizan sus conductas en términos racionales y que no expresan o muestran interés por participar en las activi-

Aesthetics in the Modern Social Order, Cambridge, Polity Press, 1994, y U. BECK, La sociedad del riesgo. Hacia una nueva modernidad, Barcelona, Paidós Ibérica, 1998.

83 D. MonjARDET, «La pensée utopique et les couches moyennes: quelques hypothèses», Sociologie du Travail, núm. 1 (1984), pp. 50-63, en A. VAN ZANTEN, «Reflexividad y elección de la escuela por los padres...», op. cit., p. 251.

84 A. Petersen, «Risk, Governance and the New Public Health», en A. Petersen y R. BurTON (eds.), Foucault, Health and Medicine, London-New York, Routledge, 1997, pp. 190-191.

85 S. Lash y J. Urri, Economies of Signs and Space, London, Sage, 1994, pp. 38-46, en A. Petersen, «Risk, Governance and the New...», op. cit.

${ }^{86}$ R. CASTEL, La metamorfosis de la cuestión social... op. cit., pp. 281-298, en A. PeterSEN, «Risk, Governance and the New...», op. cit., p. 192.

87 A. DíAZ DE RADA, «¿Qué obstáculos encuentra la etnografía cuando se practica en las instituciones escolares?», en A. Franzé, M. I. Jociles y B. Martín et al. (eds.), Actas de la Primera Reunión Científica Internacional de Etnografía y Educación (julio de 2004), Valencia, Germanía, 2005, pp. 17-52. 
dades de inserción que ofrecen las instituciones, bloqueando así las posibilidades de trabajo profesional, dado que este — como se ha dicho más atrás- necesita del compromiso del sujeto excluido como elemento básico para comenzar la intervención social (o lo que es lo mismo, para poder «consensuar» el PII).

Los trabajadores sociales que mantienen una concepción del sujeto como actor racional, libre de constricciones sociales, son los que entienden que las políticas sociales están justificadas en los casos de personas extremadamente necesitadas, mientras que, para el resto, son los valores del trabajo, el esfuerzo y la autonomía los que garantizan la cohesión social. Así, critican a quienes dependen de prestaciones económicas del Estado y cuestionan, apelando a principios liberales, la «dependencia» que ocasionan esas prestaciones y su efecto de restar iniciativa a los individuos ${ }^{88}$. Autores como Laval y Dartot ${ }^{89}$ señalan el papel de la racionalidad neoliberal en el ensalzamiento del individuo emprendedor, dotado de libertad y autonomía, y la capacidad de cuidarse adecuadamente a sí mismo. También López Varas ${ }^{90}$, refiriéndose al contexto madrileño, sostiene que la clase media critica que el gobierno sea demasiado permisivo con las capas marginalizadas de la sociedad y, particularmente, con los gitanos.

En concordancia con estas ideas, algunos profesionales están en contra de las medidas de acción positiva para los más excluidos y afirman que los mismos derechos y obligaciones deberían corresponder «a todo el mundo». De este modo, asumen la filosofía de un ascenso meritocrático y paulatino a través del trabajo, el ahorro y el sacrificio que caracteriza la moral de las clases medias ${ }^{91}$. Consecuentemente, los gitanos perceptores de la RMI con una larga historia de contacto con los servicios sociales son descritos como sujetos «cronificados», tal como también se ha indicado, dejándose traslucir así una visión negativa de las políticas sociales redistributivas ${ }^{92}$ :

88 Vid. E. M. JuAN, «La respuesta de los servicios sociales ante los procesos de exclusión social...», op. cit.; G. BuRCHELL, «Liberal Governement and Techniques of the Self», en A. Barry, T. Osborne y N. Rose (eds.), Foucault and Political Reason: Liberalism, Neoliberalism and Rationalities of Government, Chicago, University of Chicago Press, 1996, pp. 19-36, y C. Gordon, «Government Racionality: An Introduction», en G. BuRCHEL, C. Gordon y P. Miller (eds.), The Foucault Effect: Studies in Governmentality, Chicago, University of Chicago Press, 1991.

89 C. LAVAl y P. DARDOT, La nueva razón del mundo..., op. cit.

90 M. López VARAs, «Los gitanos en el epicentro de los discursos de exclusión», Revista Archipiélago, núm. 21 (1995), pp. 71-80.

91 Ibid., p. 74.

92 E. M. JuAn, «La respuesta de los servicios sociales ante los procesos de exclusión social...», op. cit., p. 107. 
«La renta mínima se puede suspender si no cumplen el PII; hay gente que sí que cumple por la necesidad o por la personalidad, y otros que lo ven como una forma de cronificarse en el tiempo» (entrevista a técnico de la CM, treinta y siete años).

Los profesionales califican de conflictivas las relaciones que mantienen con las personas que se relacionan de una manera diferente con el conocimiento y con el mundo, relativizando así su forma de hacerlo; personas que no dotan de sentido a su experiencia en términos racionalizadores y reflexivos, y que no creen en la educación y en el empleo como mecanismos de ascenso social. Estas personas, entre las que se encuentran los miembros del colectivo gitano beneficiarios de la RMI, son penalizadas de un modo persistente, sea recordándoles sutilmente que se salen de la norma, sea diciéndoles abiertamente que sus comportamientos y actitudes son errados, de manera que se aplica con ellas la metodología de intervención social más severa como, por ejemplo, el uso de amenazas sobre la posibilidad de suspender el cobro de la prestación económica a fin de forzar su participación en las actividades que se les destinan.

Aparece, entonces, una ambigüedad esencial que recorre los discursos de todos los profesionales entrevistados: queriendo establecer una relación de ayuda con las personas perceptoras de la RMI, no cuentan con los medios para entender como válidas formas de concebir la exclusión social y el mundo de la intervención social diferentes a las suyas ni para aceptar, sin caer en su estigmatización, que determinadas personas tienen contextos sociohistóricos, económicos y culturales que dan sentido a su falta de «voluntad» o a su «incapacidad» para proyectar un cambio de posición social. Por otra parte, la falta de herramientas con que cuentan para «motivar» al colectivo gitano en particular se expresa en informes técnicos que categorizan negativamente las características socioculturales del mismo, naturalizando así su exclusión social y rectificando las representaciones que manejan sobre él basadas en su «cultura» ${ }^{93}$ y en su particular «idiosincrasia».

${ }_{33}$ D. Mosse, «Anti-Social Anthropology? Objectivity, Objection, and the Ethnography of Public Policy and Professional Communities», Journal of the Royal Anthropological Institute, vol. 12 (2006), p. 953, nota al pie. 


\section{CONCLUSIÓN}

En este artículo hemos mostrado, por un lado, cómo la legislación relativa a la RMI no logra separar los dos derechos que establece, produciéndose una serie de zonas grises, de vacíos o de dudas razonables que dan cabida a que cada profesional interprete y aplique la RMI de la forma que considere oportuna. Además, como se ha adelantado, aquellos elementos más novedosos de la ley, esto es, los que podrían dotar de más poder y autonomía a los beneficiarios para iniciar procesos de toma de decisiones informadas sobre su inserción social, no aparecen regulados en los textos legales. En contraste con dicho vacío legal, todo lo relativo al procedimiento sancionador está redactado de tal manera que se da pie a interpretaciones de la ley «interesadas», las cuales abren la posibilidad de usar dicho procedimiento como medio para presionar a los beneficiarios de la RMI hacia la «participación» (dentro de la lógica de la activación que hemos descrito precedentemente).

Por otro lado, hemos detallado cómo en el ámbito de aplicación de esta política social, el discurso neoliberal, centrado en la creencia en el actor libre que, de manera reflexiva y planificada, decide el curso de su vida, ha calado en los profesionales del trabajo social. En coherencia con lo anterior, a los sujetos que no son considerados como «verdaderamente excluidos» se les conmina a ser autónomos, a moverse («hacer algo») y a ser proactivos, esto es, a decidir con los profesionales cuál debe ser su trayectoria vital y qué van a hacer para superar su situación presente.

De esta forma, los beneficiarios de la RMI que no se piensan a sí mismos en estos términos son calificados «naturalmente» como dependientes o cronificados, naturalizando así su ausencia de deseo hacia el cambio.

De manera general, podemos afirmar que los profesionales que trabajan en este terreno no suelen plantearse que la idea de autonomía que manejan conlleva una serie de habilidades reflexivas y cognitivas, además de una serie de actitudes y de maneras de estar en el mundo que difícilmente pueden desplegar los sujetos que se encuentran en posiciones sociales de vulnerabilidad. Olvidan, por último, que el deseo se construye en unas condiciones socioeconómicas, históricas y socioculturales determinadas que, en lo que se refiere al «deseo de cambio» y, por tanto, al caso que se ha tratado en este artículo, no son precisamente aquellas en que viven los sujetos objeto de nuestro estudio. 


\section{BIBLIOGRAFÍA}

Agudo, A., «Conocimiento, lenguaje, poder e intermediación. Perspectivas contemporáneas en la antropología de las políticas públicas», Estudios Sociológicos, vol. 27, núm. 79 (2009), pp. 63-110.

Aguilar, M.; GaviRIA, M., y LAPARRA, M., El programa Ingreso Madrileño de Integración (IMI). Primera evaluación, Madrid, Consejería de Integración Social, 1993.

- La caña y el pez. Estudio sobre los salarios sociales en las Comunidades Autónomas, 1989-1994, Madrid, Fundación FOESSAM, 1995.

Aguilar, M.; Laparra, M., y PÉrez, B., La exclusión multidimensional en el espacio urbano: investigaciones de base para la elaboración del Plan contra la Exclusión de la Comunidad de Madrid, Universidad Pública de Navarra y Consejería de Servicios sociales de la Comunidad de Madrid, 2003.

Alonso, J. M., «Nuevos derechos en la Comunidad de Madrid para las personas socialmente excluidas. Breve apunte sobre la Ley de Renta Mínima de la Comunidad de Madrid», Revista del Ministerio de Trabajo y Asuntos Sociales, núm. 35 (2002), pp. 185-198.

Arendt, H., Sobre la violencia, Madrid, Alianza Editorial, 2005 [1969].

AutÈs, M., «Tres formas de desligadura», en S. KARSz, La exclusión social: bordeando sus fronteras. Definiciones y matices, Barcelona, Gedisa, 2004, pp. 15-53.

- Les paradoxes du travail social, Paris, Dunod, 2004.

Ávila, D., y Malo, M., «Manos invisibles. De la lógica neoliberal en lo social», Trabajo Social Hoy, núm. 39 (2010), pp. 137-171.

Ayala Rubio, A., «Secretos a voces: exclusión social y estrategias profesionales de construcción de la obligatoriedad en la intervención social vinculada a la Renta Mínima de Inserción (RMI) con el colectivo de etnia gitana», Cuadernos de Trabajo Social, núm. 22 (2009), pp. 19-40.

- Las políticas sociales en perspectiva socioantropológica: estudio de la gestión y aplicación de la Renta Minima de Inserción de la Comunidad de Madrid con el colectivo gitano, tesis doctoral, Universidad Complutense de Madrid, 2012, disponible en bttp://eprints.ucm.es/16247/.

Aznar, M., «Tres reflexiones en torno a la Renta Mínima de Inserción», El Boletín del Comité Español para el Bienestar Social, núm. 26 (1991).

BECK, U., La sociedad del riesgo. Hacia una nueva modernidad, Barcelona, Paidós Ibérica, 1998.

Beck, U.; Giddens, A., y Lash, S., Reflexive Modernization. Politics, Tradition and Aesthetics in the Modern Social Order, Cambridge, Polity Press, 1994.

Berger, P., y Luckmann, T., La construcción social de la realidad, Buenos Aires, Amorrortu, 1989.

Burchell, G., «Liberal Governement and Techniques of the Self», en A. Barry, T. Osborne y N. Rose (eds.), Foucault and Political Reason: Liberalism, Neo- 
liberalism and Rationalities of Government, Chicago, University of Chicago Press, 1996, pp. 19-36.

CASTEL, R., La metamorfosis de la cuestión social: una crónica del salariado, Buenos Aires, Paidós, 1997.

Demazière, D., y Dubar, C., Analyser les entretiens biographiques: l'exemple des récits d'insertion, Paris, Nathan, 1997.

DíAZ DE RADA, A., «¿Qué obstáculos encuentra la etnografía cuando se practica en las instituciones escolares?», en A. Franzé, M. I. Jociles, B. Martín, D. PoveDA y S. SAma (eds.), Actas de la Primera Reunión Cientifica Internacional de Etnografía y Educación (julio de 2004), Valencia, Germanía, 2005, pp. 17-52.

Duvoux, N., «Le RMI et les dérives de la contractualisation», en S. PAUGAM (dir.), Repenser la solidarité. L'apport des sciences sociales, Paris, Presses Universitaires de France, 2007, pp. 451-470.

- L'autonomie des assistés. Sociologie des politiques d'insertion, Paris, Presses Universitaires de France, 2009.

Fassin, D., «L'invention française de la discrimination», Revue Française de Science Politique, vol. 52, núm. 4 (2002), pp. 403-423.

- «Gobernar por los cuerpos, políticas de reconocimiento hacia los pobres y los inmigrantes en Francia», Cuadernos de Antropología Social, núm. 17 (2003), pp. $51-80$.

FERnÁNDEZ, C., y TAPIA, P., «Los itinerarios de inserción social y el trabajo en red», incluido en el material del curso «La integración social en la Comunidad de Madrid: el Plan Regional contra la Exclusión Social», organizado por el Instituto Madrileño de Administración Pública (IMAP) y por la Consejería de Familia y Asuntos Sociales (Dirección General de Voluntariado y Promoción Social), 2007, pp. 195-266.

Foucault, M., «La gubernamentalidad», en M. Foucault et al., Espacios de poder, Madrid, La Piqueta, 1981 [1978].

Franzé, A., y PARAJuÁ, D., «Políticas públicas, migración y redefinición de sujetos en contextos de vulnerabilidad», en $V$ Congreso REPS (Red Española de Política Social). Desigualdad y democracia: políticas públicas e innovación social, Barcelona, Institut de Govern i Polítiques Públiques (IGOP-UAB), 2015.

García García, S., «Hermenéutica de la queja (o análisis del micropoder en los servicios sociales)», Trabajo Social Hoy, núm. 44 (2005), pp. 49-64.

Gordon, C., «Government Racionality: An Introduction», en G. BurCHEL, C. Gordon y P. Miller (eds.), The Foucault Effect: Studies in Governmentality, Chicago, University of Chicago Press, 1991.

Gullestad, M., Picturing Pity. Pitfalls and Pleasures in Cross-Cultural Communication. Image and Word in a North Cameroon Mission, New York-Oxford, Berghahn Books, 2007.

JuAn, E. M., «La respuesta de los servicios sociales ante los procesos de exclusión social: historia de tres mujeres», Revista de Servicios Sociales y Politica Social, núm. 81 (2008), pp. 91-108. 
Lash, S., y Urry, J., Economies of Signs and Space, London, Sage, 1994.

Laval, C., y Dardot, P., La nueva razón del mundo. Ensayo sobre la sociedad neoliberal, Barcelona, Gedisa, 2013.

López VARAs, M., «Los gitanos en el epicentro de los discursos de exclusión», Revista Archipiélago, núm. 21 (1995), pp. 71-80.

Martín Giner, A., «La Renta Mínima de Inserción: contradicciones e incertidumbres», Cuadernos de Trabajo Social, vol. 20 (2007), pp. 297-307.

Martínez Román, M. A., «Género, pobreza y exclusión: diferentes conceptualizaciones y políticas públicas», en J. M. TORTOSA (coord.), Pobreza y perspectiva de género, Barcelona, Icaria, 2001, pp. 65-87.

MolledA, E., «¿Por qué decimos que "no podemos hacer intervención social”?», Cuadernos de Trabajo Social, núm. 20 (2007), pp. 139-155.

MonjARDET, D., «La pensée utopique et les couches moyennes: quelques hypothèses», Sociologie du Travail, núm. 1 (1984), pp. 50-63.

Mosse, D., Cultivating Development. An Ethnography of Aid Policy and Practice, London, Pluto Press, 2005.

— «Anti-Social Anthropology? Objectivity, Objection, and the Ethnography of Public Policy and Professional Communities», Journal of the Royal Anthropological Institute, vol. 12 (2006), pp. 935-956.

Murard, N., La morale de la question sociale, Paris, La Dispute, 2003.

Nogués, L., y Rodríguez, A., «El acompañamiento social de familias gitanas con trayectorias de marginación y exclusión residencial», Revista de Documentación Social, núm. 145 (2007), ejemplar dedicado a Re-pensar la intervención social, coordinado por G. JARAíz ARroyo y E. Ruiz Ballesteros, pp. 133-152. Incluido en el curso «La integración social en la Comunidad de Madrid: el Plan Regional contra la Exclusión Social», organizado por el Instituto Madrileño de Administración Pública (IMAP) y por la Consejería de Familia y Asuntos Sociales (Dirección General de Voluntariado y Promoción Social), 2007.

OlmedA, G., «La renta mínima garantizada. A caballo de la asistencia, la seguridad social y la política de empleo», Revista de Treball, Economia i Societat, núm. 7 (1997), pp. 33-56.

Petersen, A., «Risk, Governance and the New Public Health», en A. Petersen y R. Burton (eds.), Foucault, Health and Medicine, London-New York, Routledge, 1997.

Ramírez Hita, S., Gitanos y salud. Articulación de prácticas y saberes médicos entre los gitanos de Perpignan, tesis de doctorado, Universidad Rovira i Virgili de Tarragona, 2003.

Renes, V., y Lorenzo, F., Cuestiones y retos clave en la inclusión social. Documento provisional para debate 1, Madrid, Fundación Luis Vives, 2007.

Renes, V.; Lorenzo, F., y Chahin, A., Poniendo en práctica la Estrategia Europea para la Inclusión Social. Del plano europeo al plano local. Cuaderno Europeo 4, Madrid, Fundación Luis Vives, 2007. 
Rodríguez, A., y Zamanillo, T., «Apuntes para una valoración diagnóstica», RTS: Revista de Treball Social, núm. 127 (1992), pp. 48-54.

Rosanvallon, P., Réflexions sus la question sociale. Repenser l'État-providence, Paris, Le Seuil, 1995.

Serrano, A., y Arriba, A., ¿Pobres o excluidos? El Ingreso Madrileño en perspectiva comparada, Madrid, Fundación Argentaria, 1998.

— «El Ingreso Madrileño de Integración: revisitando sus características y algunos tópicos», en L. Moreno (ed.), Pobreza y exclusión: la «malla de seguridad» en España, Madrid, Consejo Superior de Investigaciones Científicas, 2001, pp. 257-289.

Shore, C., y Wright, S. (eds.), Anthropology of Policy: Critical Perspectives on Governance and Power, London-New York, Routledge, 1997, pp. 3-39.

Van Zanten, A., «Reflexividad y elección de la escuela por los padres de clase media en Francia», Revista de Antropología Social, vol. 16 (2007), pp. 245-278.

Williams, R., Keywords, London, Fontana, 1983.

Zamanillo, T. (coord.), Análisis diagnóstico de la investigación-acción con profesionales que realizan el acompañamiento social a beneficiarios de la RMI, Convenio entre la Consejería de Servicios Sociales y la Universidad Complutense de Madrid, documento mimeografiado, 2004. 